\title{
Cortical Inhibition Reduces Information Redundancy at Presentation of Communication Sounds in the Primary Auditory Cortex
}

\author{
Quentin Gaucher, ${ }^{1,2}$ Chloé Huetz, ${ }^{1,2}$ Boris Gourévitch, ${ }^{1,2}$ and Jean-Marc Edeline ${ }^{1,2}$ \\ ${ }^{1}$ Centre de Neuroscience de Paris-Sud, UMR CNRS 8195 and ${ }^{2}$ University Paris-Sud, 91405 Orsay cedex, France
}

In all sensory modalities, intracortical inhibition shapes the functional properties of cortical neurons but also influences the responses to natural stimuli. Studies performed in various species have revealed that auditory cortex neurons respond to conspecific vocalizations by temporal spike patterns displaying a high trial-to-trial reliability, which might result from precise timing between excitation and inhibition. Studying the guinea pig auditory cortex, we show that partial blockage of $\mathrm{GABA}_{\mathrm{A}}$ receptors by gabazine (GBZ) application $(10 \mu \mathrm{M}, \mathrm{a}$ concentration that promotes expansion of cortical receptive fields) increased the evoked firing rate and the spike-timing reliability during presentation of communication sounds (conspecific and heterospecific vocalizations), whereas $\mathrm{GABA}_{\mathrm{B}}$ receptor antagonists [10 $\mu \mathrm{M}$ saclofen; 10-50 $\mu \mathrm{M}$ CGP55845 ( $p$-3-aminopropyl-p-diethoxymethyl phosphoric acid)] had nonsignificant effects. Computing mutual information (MI) from the responses to vocalizations using either the evoked firing rate or the temporal spike patterns revealed that GBZ application increased the MI derived from the activity of single cortical site but did not change the MI derived from population activity. In addition, quantification of information redundancy showed that GBZ significantly increased redundancy at the population level. This result suggests that a potential role of intracortical inhibition is to reduce information redundancy during the processing of natural stimuli.

\section{Introduction}

The ultimate goal of any processing taking place in sensory cortices is to generate neuronal mechanisms that are fast and reliable enough for identifying and discriminating between natural stimuli. One of the main challenges of sensory physiology is to decipher these mechanisms. In the auditory cortex (ACx), several groups have provided compelling evidence indicating that the temporal spike patterns occurring at presentation of communication sounds provide the bases of a neural code for discriminating between such sounds (Narayan et al., 2006; Schnupp et al., 2006; Wang et al., 2007; Recanzone, 2008; Huetz et al., 2006, 2009). In addition, comparisons between neurometric and psychometric functions suggest that the temporal spike patterns of ACx neurons allows discrimination performance at the neuronal level that approaches those observed at the behavioral level (Narayan et al., 2007; Walker et al., 2008).

Received Dec. 26, 2012; revised May 9, 2013; accepted May 12, 2013.

Author contributions: J.-M.E. designed research; Q.G. and J.-M.E. performed research; Q.G., C.H., and B.G. contributed unpublished reagents/analytic tools; Q.G., C.H., and B.G. analyzed data; Q.G., C.H., B.G., and J.-M.E. wrote the paper.

This work was supported by grants from the National Research Agency (HearFin, Program Neuro2011; Hearing Loss, Program Neuro2006) (J.-M.E.). Q.G. was supported by a fellowship from the Ministry of State Education and Research. We thank J. J. Eggermont and G. Shaw for their generous help with the acquisition software and N. Leresche for advices on the $\mathrm{GABA}_{\mathrm{B}}$ antagonists. Special thanks to Nathalie Samson and Pascale Leblanc-Veyrac for taking care of the guinea pig colony and to Sabrina Davis for improving the language of this manuscript.

Correspondence should be addressed to Jean-Marc Edeline, Centre de Neuroscience de Paris-Sud, UMR CNRS 8195, Université Paris-Sud, Bâtiment 446, 91405 Orsay cedex, France. E-mail: jean-marc.edeline@u-psud.fr.

DOI:10.1523/JNEUROSCI.0079-13.2013

Copyright $\odot 2013$ the authors $\quad 0270-6474 / 13 / 3310713-16 \$ 15.00 / 0$
A central question now is to determine which key factors control the ability of cortical neurons to discriminate between communication sounds. In all sensory cortices, it has long been suggested that the neuron functional properties result from the interplay between excitatory and inhibitory inputs (Gilbert and Wiesel, 1985; Ebner and Armstrong-James, 1990; Calford, 2002; Hirsch, 2003; Swadlow, 2003; Oswald et al., 2006). In the ACx, previous studies have described that application of $\mathrm{GABA}_{\mathrm{A}}$ antagonists enlarges the spectral receptive fields (Wang et al., 2000, 2002) or modifies temporal modulation transfer function (Kurt et al., 2006). However, only very few attempts have been made to determine whether the balance between excitation and inhibition changes the abilities of $\mathrm{ACx}$ neurons to discriminate between natural stimuli. Disrupting intracellular $\mathrm{GABA}_{\mathrm{A}}$ or $\mathrm{GABA}_{\mathrm{B}}$ inhibition, Rosen and Mooney (2003) were unable to block neuronal selectivity for the bird's own song in zebra finch HVC neurons. In contrast, blocking $\mathrm{GABA}_{\mathrm{A}}$ receptors in the bird functional analog of nonprimary ACx (the NCM nucleus) increased the phasic components of responses to conspecific songs (Pinaud et al., 2008). Furthermore, it was shown that alterations of GABAergic inhibition (by manipulating the level of brain-generated estradiol) influence both neuronal and behavioral discriminative performances (Tremere and Pinaud, 2011). To determine the effects of intracortical inhibition on the ACx discriminative abilities, we assessed to what extent individual cortical sites and ensembles of cortical sites are affected when a partial blockage of $\mathrm{GABA}_{\mathrm{A}}$ or $\mathrm{GABA}_{\mathrm{B}}$ receptors is made on the entire ACx. To achieve this, we topically applied $\mathrm{GABA}_{\mathrm{A}}$ [gabazine $\left.(\mathrm{GBZ})\right]$ or $\mathrm{GABA}_{\mathrm{B}}$ [saclofen and CGP55845 ( $p$-3-aminopropyl- $p$-diethoxymethyl phosphoric acid) 
(CGP)] antagonists to the cortical surface while recording cells simultaneously in 16 locations of the primary ACx tonotopic map. Spectrotemporal receptive fields (STRFs) were first quantified to ensure that the drug concentration/time of application was able to induce reliable changes on the STRFs of the neurons. Then, we analyzed the response strength and the spike-timing reliability at presentation of conspecific and heterospecific vocalizations before and after drug application. We quantified the amount of mutual information (MI) carried by firing rate and temporal patterns in control and drug conditions at both the single site and population level. We found that reducing the intracortical inhibition increased the information conveyed by individual sites but left the population information unaffected, indicating that intracortical inhibition contributes to reducing redundancy between cortical sites.

\section{Materials and Methods}

\section{Subjects}

Recordings were made in the primary $\mathrm{ACx}$ of adult pigmented guinea pigs of either sex. Animals, weighing 450-950 g (3-7 months old), came from our own colony housed in a humidity-controlled (50-55\%) and temperaturecontrolled $\left(22-24^{\circ} \mathrm{C}\right)$ facility on a $12 \mathrm{~h}$ light/dark cycle (lights on at 7:30 A.M.) with access to food and water ad libitum. All surgical procedures were performed in compliance with the guidelines determined by the national (JO 887-848) and European (86/609/EEC) legislations on animal experimentation, which are similar to those described in the Guidelines for the Use of Animals in Neuroscience Research of the Society of Neuroscience. Two to $3 \mathrm{~d}$ before each experiment, the animal's audiogram was determined by testing auditory brainstem responses (ABRs) under isoflurane anesthesia $(2.5 \%)$, described previously by Gourévitch et al. (2009). The ABR was obtained by differential recordings between two subdermal electrodes (SC25; NeuroService) placed at the vertex and behind the mastoid bone. Averages of 500 responses were collected at nine frequencies (between 0.5 and $32 \mathrm{kHz}$ ) presented between 70 and $0 \mathrm{~dB}$ SPL to obtain the audiogram. All the animals used in the present study showed audiogram in the range reported previously for healthy guinea pigs (Robertson and Irvine, 1989; Gourévitch and Edeline, 2011).

\section{Surgical procedures}

The animal was anesthetized by an initial injection of urethane $(1.2 \mathrm{~g} / \mathrm{kg}$, i.p. $)$ supplemented by additional doses $(0.5 \mathrm{~g} / \mathrm{kg}$, i.p.) when reflex movements were observed after pinching the hindpaw (usually once or twice during the recording session). A single dose of atropine sulfate $(0.06 \mathrm{mg} / \mathrm{kg}$, s.c.) was given to reduce bronchial secretions. After placing the animal in a stereotaxic frame, a craniotomy was performed above the left temporal cortex. A local anesthetic ( $2 \%$ xylocaine) was liberally injected in the wound. The opening was $8 \mathrm{~mm}$ wide starting at the intersection point between parietal and temporal bones and $8-10 \mathrm{~mm}$ in height. The dura above the $\mathrm{ACx}$ was removed under binocular control, and the CSF was drained through the cysterna magna to prevent the occurrence of edema. After the surgery, a pedestal of dental acrylic cement was built to allow atraumatic fixation of the animal's head during the recording session. The stereotaxic frame supporting the animal was placed in a sound-attenuating chamber (model AC1; IAC). At the end of the recording session, a lethal dose of pentobarbital $(>200 \mathrm{mg} / \mathrm{kg}$, i.p.) was administered to the animal.

\section{Recording procedures}

Data are from multiunit recordings in the primary ACx (area AI). Extracellular recordings were obtained from arrays of 16 tungsten electrodes ( $33 \mu \mathrm{m}$ diameter, $<1 \mathrm{M} \Omega$ ) composed of two rows of eight electrodes separated by $1000 \mu \mathrm{m}$ ( $350 \mu \mathrm{m}$ between electrodes of the same row). A silver wire, used as ground, was inserted between the temporal bone and the dura mater on the contralateral side. The location of the primary ACx was estimated based on the pattern of vasculature observed in previous studies (Edeline and Weinberger, 1993; Manunta and Edeline, 1999; Wallace et al., 2000; Edeline et al., 2001). The raw signal was amplified 10,000 times (Medusa; Tucker-Davis Technologies) and was then processed by an RX5 multichannel data acquisition system (Tucker-Davis Technologies). The signal collected from each electrode was filtered $(610-10,000 \mathrm{~Hz})$ to extract multiunit activity (MUA).
The trigger level was set for each electrode to select the largest action potentials from the signal and was the same before and after drug application. Online and offline examination of the waveforms suggests that the MUA collected here was made of action potentials generated by three to eight neurons in the vicinity of the electrode. At the beginning of each experiment, we set the position of the electrode array in such a way that the two rows of eight electrodes sampled neurons responding from low to high frequency when progressing in the rostrocaudal direction (see example of tonotopic maps recorded with such an array in the study by Gaucher et al., 2012, their Fig. 1).

\section{Drug delivery}

Topical application allows application of pharmacological agents on cortical areas and has been used previously in several brain regions (Riquimaroux et al., 1991, 1992; Jones and Barth, 2002; Caesar et al., 2003, 2008; Yu et al., 2008; Wang et al., 2009). Here, this technique was used because we aimed at assessing the consequences of GABA receptor blockage over the whole cortical map. During this manipulation, neuronal responses were simultaneously sampled from 16 different locations in the primary ACx. Several pilot studies were performed to determine (1) the GBZ concentration to be used and (2) the time course of the GBZ effect on ACx neurons. First, we looked for GBZ concentrations that can be applied in vivo without triggering epileptiform neuronal activity. Based on several in vivo studies (Darbin et al., 2006; Darbin and Wichmann, 2008; Tachibana et al., 2008; Wang et al., 2009), we opted for a 10 $\mu \mathrm{M}$ GBZ concentration. However, this low concentration can still lead to abnormal (seizure-like) activities when continuously applied to the surface of the cortex. For this reason, we applied the drug only for a brief period via a filter paper $(\sim 0.7 \times 2.5 \mathrm{~mm})$ placed in close vicinity to the electrode array. Initially, two durations of drug application were used in our experiments: 2 and $4 \mathrm{~min}$. However, we noted that the $2 \mathrm{~min}$ application protocol did not induce effects significantly different from spontaneous fluctuations or from application of saline. Moreover, in another set of experiments performed with multichannel silicon probe electrodes (16 channels; A-Style probe; NeuroNexus), we assessed the magnitude of GBZ effects as a function of the cortical layer. A 2 min application induced significant effects on the STRF parameters from layer I to layer IV but not in layers V-VI (Fig. $1 A$ ). In contrast, a 4 min application induced a strong effect on the STRF parameters in all cortical layers (Fig. 1B). For these reasons, results presented here are only those obtained with a 4 min application protocol. In these conditions, there was an increase in evoked activity starting in $<10 \mathrm{~min}$ after drug application and remaining above the control level for $>60 \mathrm{~min}$ (Fig. 1C). With this protocol, epileptiform activity was never observed. Because the two $\mathrm{GABA}_{\mathrm{B}}$ antagonists used in our study (saclofen and CGP) have molecular weights similar to GBZ, we assumed that their effects should have a similar time course. All drugs were freshly dissolved on the day of the experiment and kept at $38^{\circ} \mathrm{C}$ until application on the cortical surface.

\section{Acoustic stimuli}

Artificial stimuli. Acoustic stimuli were generated in MATLAB (MathWorks), transferred to an RP2.1-based sound delivery system (Tucker-Davis Technologies) and sent to a Fostex speaker (FE87E). The speaker was placed at 2 $\mathrm{cm}$ from the guinea pig's right ear, a distance at which the speaker produced a flat spectrum $( \pm 3 \mathrm{~dB})$ between $140 \mathrm{~Hz}$ and $36 \mathrm{kHz}$. Calibration of the speaker was made using noise and pure tones recorded by a microphone (4133; Brüel \& Kjær) coupled to a preamplifier (2169; Brüel \& Kjær) and a digital recorder (PMD671; Marantz). The STRFs were determined using 97 or 129 gamma-tone frequencies, covering six $(0.14-9,0.28-18$, or $0.56-36$ $\mathrm{kHz})$ or eight $(0.14-36 \mathrm{kHz})$ octaves, respectively, and presented at three intensities: (1) 85 or $75 \mathrm{~dB}$ SPL; (2) 65 or $55 \mathrm{~dB} \mathrm{SPL}$; and (3) 45 or $35 \mathrm{~dB}$ SPL. At a given intensity, each frequency was repeated eight times at a rate of 2.35 $\mathrm{Hz}$ in pseudorandom order. The duration of these tones over half-peak amplitude was $15 \mathrm{~ms}$ and the total duration of the tone was $50 \mathrm{~ms}$, so there was no overlap between tones.

Natural stimuli. A set of three conspecific and five heterospecific vocalizations was used to assess the neuronal response to communication sounds. The conspecific vocalizations were recorded from animals of our colony. Pairs of animals were placed in the acoustic chamber, and their 

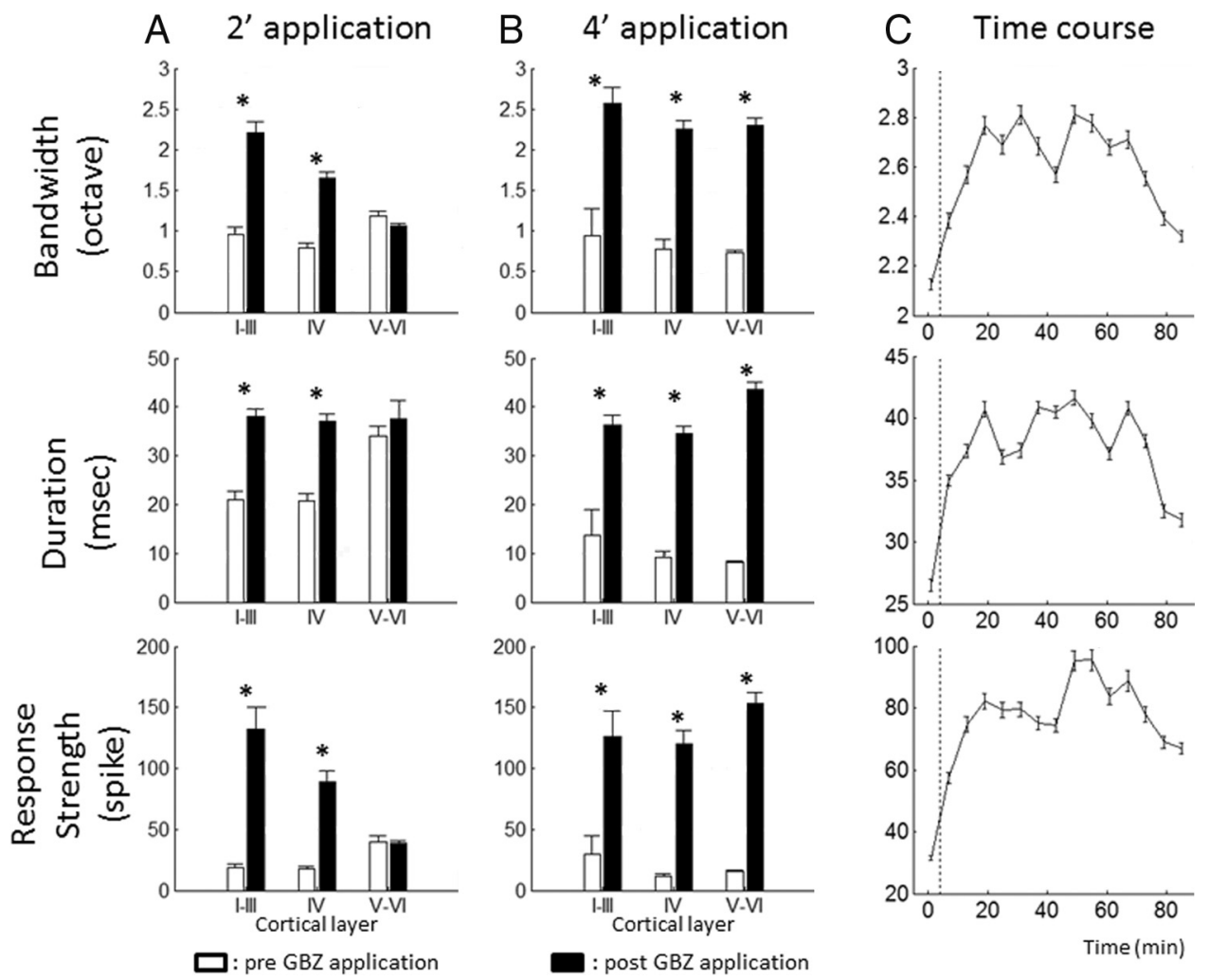

Figure 1. Spatial and temporal extents of GBZ effects on STRFs. Group data showing the effects of GBZ application on the STRF parameters for a 2 and 4 min application ( $\boldsymbol{A}$ and $\boldsymbol{B}$, respectively; each line corresponds to one STRF parameter: bandwidth, duration, and response strength). Data are expressed as mean \pm SEM. White bars, Before application; black bars, after application. Note that the effects of a 2 min application were clear in layers I-III and IV but were not detected in layers V-VI. In contrast, a 4 min application led to an increase of the STRF parameters in all cortical layers. In addition, 4 min application led to stronger effects than $2 \mathrm{~min}$ application. The limits between layers were assigned using previous descriptions of the guinea pig ACx by Wallace and Palmer (2008): the upper and lower limits of layer IV were 800 and $1200 \mu \mathrm{m}$, respectively. Recordings obtained before $800 \mu \mathrm{m}$ were assigned to layers I-III; recordings obtained below $1200 \mu \mathrm{m}$ were assigned to layers V-VI. C shows the effects of GBZ on the STRF parameters. Data (3 animals, 39 recordings) are expressed as mean \pm SEM after a 4 min, $10 \mu \mathrm{m}$ application. For each curve, the first point was obtained before GBZ application. These curves indicate that our effects were partially reversible and that, $60 \mathrm{~min}$ after GBZ application, the STRF parameters tended to come back to the initial values. ${ }^{*} p$ value $<0.05$.

vocalizations were recorded by a microphone (4133; Brüel \& Kjær) coupled to a preamplifier (2169; Brüel \& Kjær) and a digital recorder (PMD671; Marantz). A large set of vocalizations was loaded in the Audition software (Adobe Audition 3; Adobe Systems), and representative examples of a purr, a chutter, and a whistle were selected. Three heterospecific vocalizations were selected to approximately match the conspecific vocalizations in terms of both the spectral content and the frequency and amplitude modulations according to visual inspection of their spectrograms. The heterospecific vocalizations were not modified to equalize their modulation power spectra relative to the conspecific ones. These vocalizations were a dolphin chutter, a rabbit whistle, and a dove purr. The two other heterospecific vocalizations were selected to be strongly different from conspecific vocalizations and included a Marsh Warbler song and a low-frequency call from a wart-biter cricket. All heterospecific vocalizations were downloaded from the Macaulay Library of the Cornell laboratory of Ornithology (http://macaulaylibrary. org/index.do). Figure 2 shows the spectrograms and envelops of the three conspecific vocalizations and their heterospecific counterparts.

\section{Experimental protocol}

Inserting an array of 16 electrodes in the cortical tissue almost systematically induces a deformation of the cortex. At least a 30 min recovering time lapse was allowed for the cortex to return to its initial shape, and then the array was slowly lowered. STRFs were used to assess the quality of our recordings and to adjust the electrodes depth. The recording depth was $500-1000 \mu \mathrm{m}$, which corresponds to layer III and the upper part of layer IV according to Wallace and Palmer (2008). However, as a result of the convex shape of the guinea pig ACx, it is likely that all the electrodes were not exactly at the same depth.
When a clear tuning was obtained for at least 8 of the 16 electrodes, the stability of the tuning was assessed: we required that the recordings displayed at least three successive similar STRFs (each lasting $6 \mathrm{~min}$ ) before starting the protocol. When the stability was satisfactory, the protocol started by presenting the acoustic stimuli in the following order: gamma tones to determine the STRF at three intensities (18 min in total), followed by 3 min of spontaneous activity, followed by conspecific and heterospecific vocalizations presented at $75 \mathrm{~dB}$ SPL. Each vocalization was repeated 20 times. Presentation of this entire stimulus set lasted 30 $\mathrm{min}$ and was followed by the $4 \mathrm{~min}$ period of drug application. The same set of stimuli was presented immediately after drug application in the same order and then $1 \mathrm{~h}$ after when the recordings were stable.

\section{Data analyses}

Quantification of responses to pure tones. The STRFs derived from MUA were obtained by constructing poststimulus time histograms (PSTHs) for each frequency with $1 \mathrm{~ms}$ time bins. All spikes falling in the averaging time window (starting at stimulus onset and lasting $100 \mathrm{~ms}$ ) were counted. Thus, STRFs are matrices of 100 bins in abscissa (time) multiplied by 97 or 129 bins in ordinate (frequency). All STRFs were smoothed with a uniform $5 \times 5$ bin window.

For each STRF, at a given intensity, the best frequency was defined as the frequency at which the highest firing rate was recorded. At each intensity, peaks of significant response were automatically identified using the following procedure: a positive peak in the multiunit-based STRF was defined as a contour of firing rate above the average level of the baseline activity (estimated from the first $10 \mathrm{~ms}$ of STRFs at all intensity levels) plus six times the $\mathrm{SD}$ of the baseline activity. For a given site and a given intensity, three measures were extracted from the peaks and one directly from the spike trains. 


\section{Conspecific}

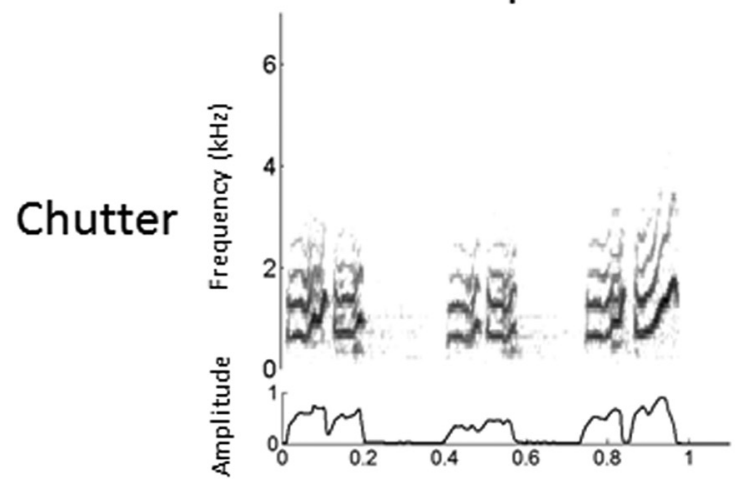

Whistle

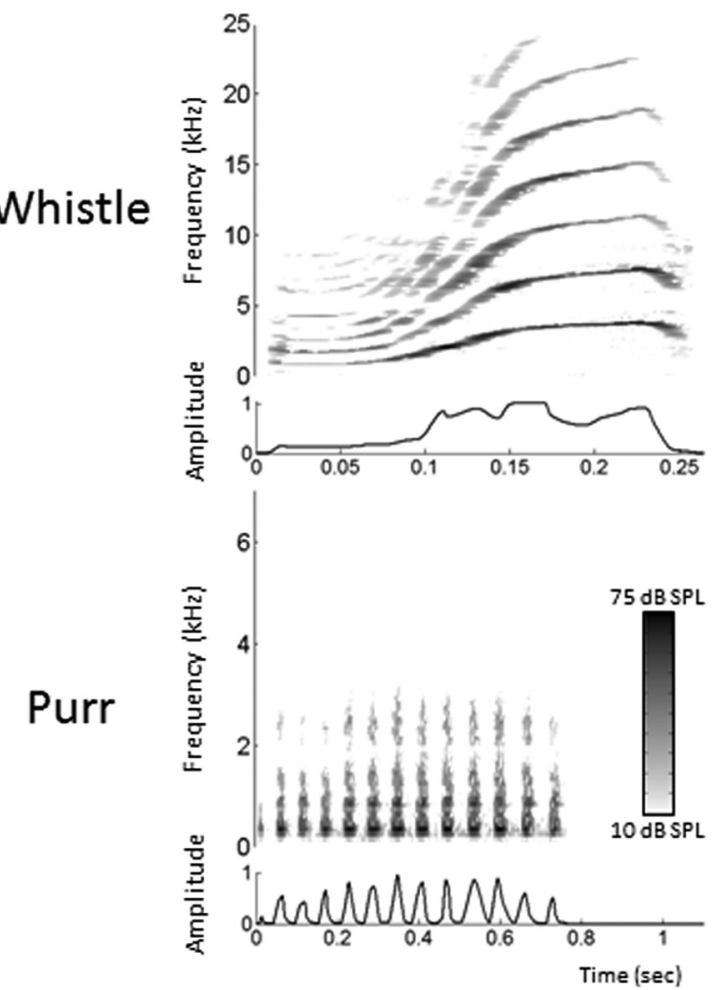

\section{Heterospecific}

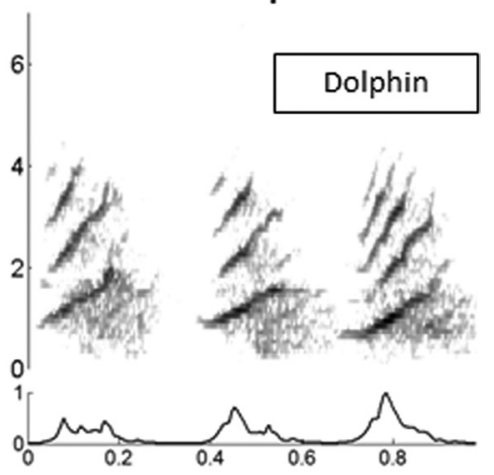

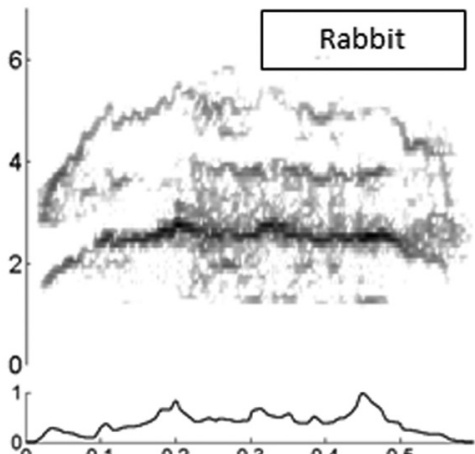

Dove

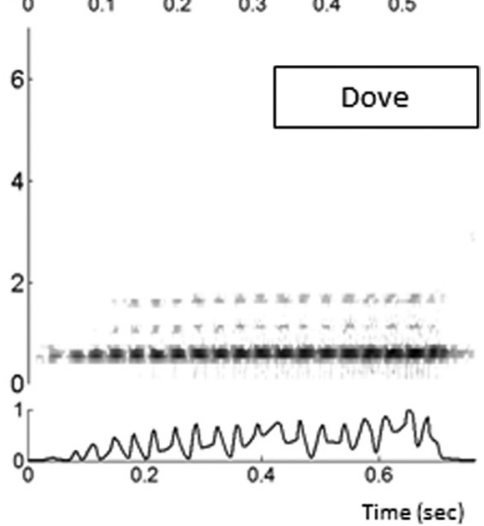

Figure 2. Spectrograms of six vocalizations used to test the neuronal responses. Each row corresponds to one vocalization (Chutter, Whistle, and Purr). The spectrograms of the left column correspond to conspecific vocalizations, and those of the right column correspond to heterospecific vocalizations approximately matching the conspecific ones. The envelope of each vocalization is displayed under each spectrogram.

First, the "total bandwidth" was defined as the sum of all peak widths in octaves. Second, the "response duration" was the time difference between the first and last spikes of the significant peaks. Third, the "response strength" was the total number of spikes falling in the significant peaks. In addition, we computed the "temporal precision" of the spike trains corresponding to the STRF excitatory area. This was done by computing the shuffled autocorrelogram (SAC) (Joris 2003) for all pairs of spike trains evoked by the pure tones within the STRF bandwidth. The SAC was then fitted to the following equation (Elhilali et al., 2004; Chen et al., 2012):

$$
R(t)=\lambda^{2}+\frac{\alpha \lambda}{\sigma \sqrt{2 \pi}} e^{-t^{2} / 2 \sigma^{2}},
$$

where $\alpha$ is the firing reliability, $\lambda$ is the firing rate, and $\sigma^{2}$ is the spiketiming jitter variance. The parameter $\sigma$ and $\alpha$ were obtained by fitting the model to the experimentally measured shuffled correlogram using constrained least-squares optimization. The $\sigma$ parameter corresponds to the encoding window, denoted ET in the study by Chen et al. (2012). The encoding window was extracted for all sites for which a good fit $(r>0.6)$ could be obtained. Note that the integrating window (denoted IT) defined by these authors was computed exactly as our response duration.

Quantification of responses evoked by vocalizations. The responses to vocalizations were quantified using three parameters: (1) the evoked response, which corresponds to the difference between evoked and spontaneous firing rates at presentation of the vocalizations; (2) the encoding window computed from the SAC using the same method as for the STRF (see above); and (3) the spike-timing reliability coefficient (CorrCoef), which was used to quantify the trial-to-trial reliability of the responses. This index was computed for each vocalization: it corresponds to the normalized covariance between each pair of action potential trains recorded at presentation of this vocalization and was calculated as follows:

$$
\text { CorrCoef }=\frac{1}{N(N-1)} \sum_{i=1}^{N-1} \sum_{j=i+1}^{N} \frac{\sigma x_{i} x_{j}}{\sigma x_{i} \sigma x_{j}}
$$

where $N$ is the number of trials, and $\sigma x_{i} x_{j}$ is the normalized covariance at zero lag between spike trains $x_{i}$ and $x_{j}$, where $i$ and $j$ are the trial numbers. 
Spike trains $x_{i}$ and $x_{j}$ were previously convolved with a 10 -ms-width Gaussian window. This value was chosen according to the analysis of the temporal precision maximizing the MI. This analysis revealed that the maximal information was obtained for $8 \mathrm{~ms}$ in average (data not shown).

The CorrCoef was used because our simulations indicated that it was not influenced by fluctuations of firing rate. In these simulations, the firing rate influence on CorrCoef values was studied using homogenous Poisson spike-train simulations. In a first set of simulations, we computed the CorrCoef for 50 surrogate spike trains with various firing rates showing no spike-timing reliability (Poisson spike trains). The CorrCoef stayed $\sim 0$ for every firing rate tested. In a second set of simulations, we generated a spike train with a relatively high value of CorrCoef $(\sim 0.4)$; then we added spikes at random time points within this spike train to quantify putative variations of the CorrCoef in a situation mimicking the natural neuronal response. Here again, this index did not increase with random additions of action potentials. Thus, the CorrCoef index does not depend on the firing rate variations. These simulations also allowed computing the chance level of the CorrCoef value: 0.026 for a 0.01 confidence interval.

To discard recordings not responding to any vocalization, we set up a criterion of an evoked firing rate of at least 1.5 spikes/s or a CorrCoef of at least 0.15 . A systematic and meticulous examination of our database has shown that recordings exhibiting only a phasic onset response generated a CorrCoef of at least 0.15 and that cells responding by tonic responses lacking temporal organization generated at least a firing rate of 1.5 spikes/s.

Quantification of correlations between pairs of neurons. Another way to evaluate neuronal reliability at the level of pair of neurons is to perform an analysis of noise and signal correlations, as described by Averbeck et al. (2006). In a set of interesting studies (Latham and Nirenberg, 2005; Averbeck and Lee, 2006; Averbeck et al., 2006), these authors pointed out that it is possible to dissociate between noise correlations (i.e., the firing rate correlation for a pair of neurons in response to presentations of the same stimulus) versus signal correlation (i.e., the correlation between the mean responses of the same pair of neurons to different stimuli). Noise correlations, if present, reflect the existence of a connection between two recording sites, without making assumptions on the anatomical circuitry of this connection. They only represent a covariation of the variability of the recording site responses. Signal correlations reflect a co-tuning of a pair of recording sites. Noise and signal correlations between pairs of recordings sites were computed with exactly the same procedure for vocalizations and pure tones. To compute noise correlation, the firing rate of neuronal responses to each stimulus was first normalized by the average firing rate in response to this stimulus. Then the normalized firing rates in response to each presentation of each stimulus were taken for a pair of recordings, and the Pearson's correlation coefficient between them was computed. The values of the Pearson's coefficient for each pair of recordings were then averaged. To compute the signal correlation, we computed the Pearson's coefficient between the mean responses to each stimulus from a pair of recordings. We then averaged the result for all pairs of recordings.

Quantification of MI from the responses to vocalizations. We used an indirect method (Schnupp et al., 2006) to quantify the amount of information (Shannon, 1948) contained in the responses to vocalizations obtained in control conditions and after application of GABAergic antagonists. This method allows quantifying how well the identity of the vocalization can be inferred from the neuronal responses. Here, "neuronal responses" refers to either the spike trains recorded under one single electrode in response to one stimulus (for the computation of the individual MI) or a concatenation of spike trains simultaneously recorded under several electrodes (for the computation of the population MI). In both cases, the following computation steps were the same. Neuronal responses can be represented using different timescales ranging from the whole response (firing rate) to a $1 \mathrm{~ms}$ precision (precise temporal patterns), which allows analyzing how much the spike timing contributes to the information. Because this method is exhaustively described by Schnupp et al. (2006), we will present here only the main principles.

The method relies on a pattern recognition algorithm that is designed to "guess which stimulus evoked a particular response pattern" by going through the following steps. From all the responses of a cortical site to the different stimuli, a single response (test pattern) is extracted and represented as a PSTH with a given bin size (different sizes were considered as discussed further below). Then, from the remaining responses (training set), a mean response pattern is computed for each stimulus class. The test pattern is then assigned to the stimulus class of the closest mean response pattern. This operation is repeated for all the responses, generating a confusion matrix in which each response is assigned to a given stimulus class. From this confusion matrix, the MI is given by Shannon's formula:

$$
\mathrm{MI}=\sum_{x, y} p(x, y) \times \log _{2} \frac{p(x, y)}{p(x) \times p(y)},
$$

where $x$ and $y$ are the rows and columns of the confusion matrix or, in other words, the values taken by the random variables "presented stimulus class" and "assigned stimulus class."

In our case, we used responses to the eight vocalizations and selected the first $264 \mathrm{~ms}$ of these responses to work on spike trains of the same duration, with the shortest vocalization being $264 \mathrm{~ms}$ long (conspecific whistle). In a scenario in which the responses do not carry any information, the assignments of each response to a mean response pattern will be equivalent to chance level (here $1 / 8$ because we used eight different stimuli and each stimulus was presented the same number of times) and the MI would be close to zero. In the opposite case in which responses are very different between stimulus classes and very similar within a stimulus class, the confusion matrix would be diagonal and the MI would tend to $\log _{2}(8)=3$ bits.

As already stated, this algorithm was applied at different bin sizes ranging from 264 to $1 \mathrm{~ms}$. For each cortical site, two parameters were extracted from this analysis: (1) the value of MI for the largest bin size, $264 \mathrm{~ms}$, which represents the value of MI when only the firing rate is considered (when no temporal patterns are considered); and (2) the value of MI obtained for a bin of $8 \mathrm{~ms}$, which was a temporal resolution leading to the highest values of information in previous studies (Schnupp et al., 2006; Huetz et al., 2009).

The MI estimates are subject to non-negligible positive sampling biases. Therefore, as in the study by Schnupp et al. (2006), we estimated the expected size of this bias by calculating MI values for "shuffled" data, in which the response patterns were randomly reassigned to stimulus classes. The shuffling was repeated 100 times, resulting in $100 \mathrm{MI}$ estimates of the bias $\left(\mathrm{MI}_{\text {bias }}\right)$. These $\mathrm{MI}_{\text {bias }}$ estimates are then used as estimators for the computation of the statistical significance of the MI estimate for the real (unshuffled) datasets: the real estimate is considered significant if its value is statistically different from the distribution of $\mathrm{MI}_{\text {bias }}$ shuffled estimates. Significant MI estimates were computed for MI calculated from neuronal responses under one electrode.

To assess whether drug-induced alterations of the firing rate account for any change in the information carried by the temporal patterns, we performed spike count normalizations between pre-conditions and post-conditions as described by Tremere and Pinaud (2011). For each cortical site, spikes were randomly removed or added from the postapplication cortical responses to exactly match the pre-application firing rate. For the spike additions, pseudorandom values were drawn from a Poisson distribution, and spikes were inserted at these random arrival times. For the spike removals, spike arrival times were randomly selected among all spikes evoked by a vocalization (all trials) and removed. For each cortical site, spike count normalization was performed 50 times, and the mean MI value was taken. As stated in Results, this normalization did not significantly affect the MI values at the precision under study $(8 \mathrm{~ms}$ bin size).

Quantification of redundancy in the responses to vocalizations. We computed the redundancy in neuronal responses according to the method described in previous studies (Narayanan et al., 2005; So et al., 2012). This method relied on the comparison between the information carried by a group of simultaneously recorded neuronal responses and the sum of information carried by each individual recording from the same group. In our study, the information carried by a group of recording was estimated by the population MI ( $\left.\mathrm{MI}_{\text {population }}\right)$, and the information car- 
ried by one recording was estimated by the individual $\mathrm{MI}\left(\mathrm{MI}_{\text {individual }}\right)$. Formally, the redundancy (called $\mathrm{P}_{\text {ensemble }}$ by Narayanan et al., 2005; So et al., 2012) was defined as follows:

$$
\mathrm{P}_{\text {ensemble }}=\mathrm{MI}_{\text {population }}-\sum_{i=1}^{N} \mathrm{MI}_{\text {individual }}
$$

where $N$ is the number of recordings used to compute the $\mathrm{MI}_{\text {population }}$. When $\mathrm{P}_{\text {ensemble }}$ was positive, neuronal responses were considered synergistic. On the contrary, when $\mathrm{P}_{\text {ensemble }}$ was negative, the neuronal responses were redundant.

In practice, we could record from 16 cortical sites simultaneously, so the $\mathrm{P}_{\text {ensemble }}$ was computed using a maximum of 16 recordings, from which the non-responsive ones were excluded. To assess the influence of the group size of simultaneous recordings on the information carried by that group $\left(\mathrm{MI}_{\text {population }}\right)$, the number of sites used for computing $\mathrm{MI}_{\text {population }}$ varied from two to the maximal possible size (equivalent to 16 minus the non-responsive sites). Because the number of possible combinations could be extremely large $\left(C_{n}{ }^{k}\right.$, where $k$ is the group size and $n$ is the number of responsive sites in a recording session), a threshold was fixed to reduce computation time: when the number of possible combinations exceeded 100,100 combinations were randomly chosen. Otherwise, the $\mathrm{P}_{\text {ensemble }}$ values were computed for all possible combinations.

In all the results, data are presented as mean \pm SEM values, and all the statistical tests are paired $t$ tests unless otherwise specified. We used a significance level of 0.05 with Bonferroni's corrections for multiple tests.

\section{Results}

Application of GBZ was tested on five animals, which provided 77 stable recordings throughout the recording session. Saclofen application was tested in seven animals, which provided 92 recordings. CGP was tested in nine animals, which provided 125 recordings ( 4 animals/60 recordings for $10 \mu \mathrm{M}$ and 5 animals/65 recordings for $50 \mu \mathrm{M}$ ). Saline application was performed on a separate set of three animals, providing 73 recordings. In the following presentation of the results, we will first describe the effects of the three GABA antagonists on the STRF parameters and then on the responses to conspecific and heterospecific vocalizations.

Analyzing spontaneous activity (recorded during a $3 \mathrm{~min}$ silence period) revealed that GBZ primarily increased spontaneous activity (by 77\%), whereas application of the two $\mathrm{GABA}_{\mathrm{B}}$ antagonists led to smaller effects: $41 \%$ for saclofen and $20 \%$ for CGP. Note that the increase for CGP is in the range of the changes observed in control conditions: saline application led to a $21 \%$ increase in spontaneous activity (see Discussion).

\section{Effects of the GABA antagonists on STRFs}

In most cases, application of the $\mathrm{GABA}_{\mathrm{A}}$ antagonist GBZ induced three striking effects on the STRFs of the neurons: there was a large increase in (1) the bandwidth of the suprathreshold tuning, (2) the duration of evoked response, and (3) the response strength. Figure $3 A$ illustrates these effects: the best frequency of this recording was at $25 \mathrm{kHz}$ at $75 \mathrm{~dB}$ SPL (Fig. $3 A$, pre), and it expanded in the low-frequency side both immediately after and

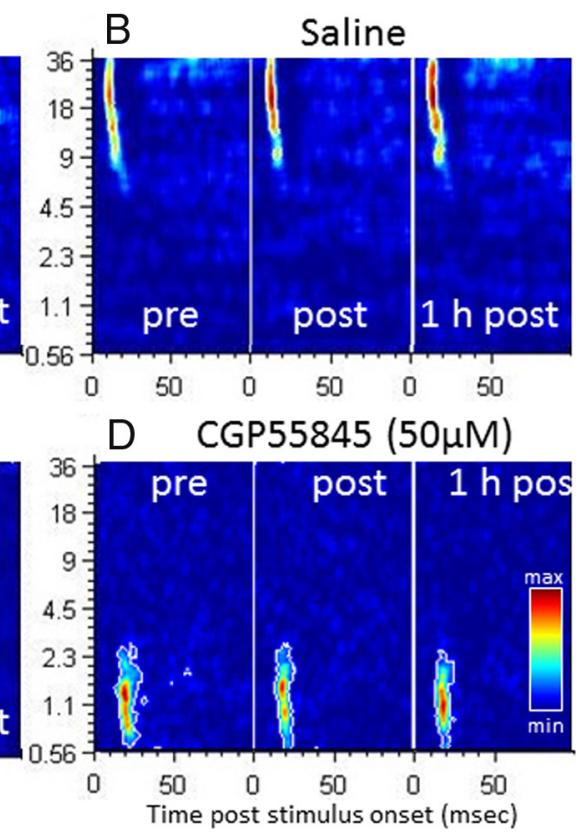

Gabazine

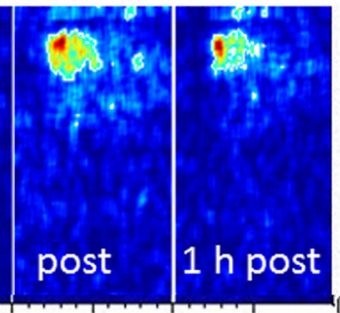

$50 \quad 0 \quad 50$

M)

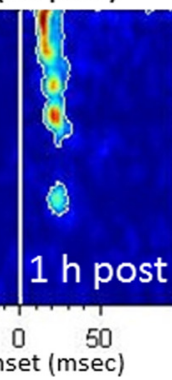

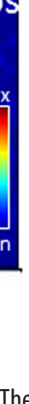

Figure 3. Examples of STRFs obtained during application of GBZ (A), saline (B), CGP at $10 \mu \mathrm{M}(\boldsymbol{C})$, and $(G P$ at $50 \mu \mathrm{M}(\boldsymbol{D})$. The omains and increased the firing rate $(\boldsymbol{A})$. In contrast, (GP tested at two concentrations (10 $\mu \mathrm{m}$ in $\boldsymbol{C} ; 50 \mu \mathrm{m}$ in $\boldsymbol{D})$ produced modest increases in firing rate similar to those obtained after saline $(\boldsymbol{B})$ application.

$1 \mathrm{~h}$ after application. As indicated by the color code, the response strength also increased, as did the response duration. In contrast, the $\mathrm{GABA}_{\mathrm{B}}$ antagonists (saclofen and CGP) induced only small or no effects. Figure 3, $C$ and $D$, presents two examples of STRFs obtained after application of CGP at 10 and $50 \mu \mathrm{M}$. In both cases, there was no change in response bandwidth, strength, and duration immediately after and $1 \mathrm{~h}$ after application. Figure $3 B$ presents an example of STRFs obtained before and after saline application: there was a slight increase in response strength but no change in tuning bandwidth or response duration.

Across all the tested intensities, the group data confirmed that the striking modulation exerted by $\mathrm{GABA}_{\mathrm{A}}$ receptors on the STRF parameters (Fig. 4). On average, GBZ produced a significant increase in bandwidth (from $1 \pm 0.09$ to $1.7 \pm 0.17$ octave; $p<0.001$ ), response duration (from $21.7 \pm 2.25$ to $39.9 \pm 2.74$ $\mathrm{ms} ; p<0.001$ ), and response strength (from $12.2 \pm 1.69$ to $71.1 \pm 12.9$ spikes; $p<0.001)$. The encoding window derived from the response autocorrelogram was also significantly increased (from $6.55 \pm 1.29$ to $15.31 \pm 1.75 \mathrm{~ms} ; p<0.001$; data not shown). In contrast, saline application and application of $\mathrm{GABA}_{\mathrm{B}}$ antagonists did not induce significant effects on bandwidth and duration of evoked responses (Fig. 4). The only significant effects observed were a slight increase in response strength with CGP tested at $10 \mu \mathrm{M}$ and a decrease with the same drug at a concentration of $50 \mu \mathrm{M}$. The encoding window was also unaffected by saline or $\mathrm{GABA}_{\mathrm{B}}$ antagonists (data not shown).

It could be suspected that the effects induced by GBZ differ with the stimuli intensity (i.e., can differ at suprathreshold intensities vs close to threshold intensities). Analyzing the effects of GBZ at three groups of intensities ( $\geq 75,65$, and $\leq 55 \mathrm{~dB} \mathrm{SPL})$ did not reveal major differences (data not shown). Response strength and the response duration were increased at the three intensities $(p<0.001$ in all cases). The bandwidth was increased at the two 

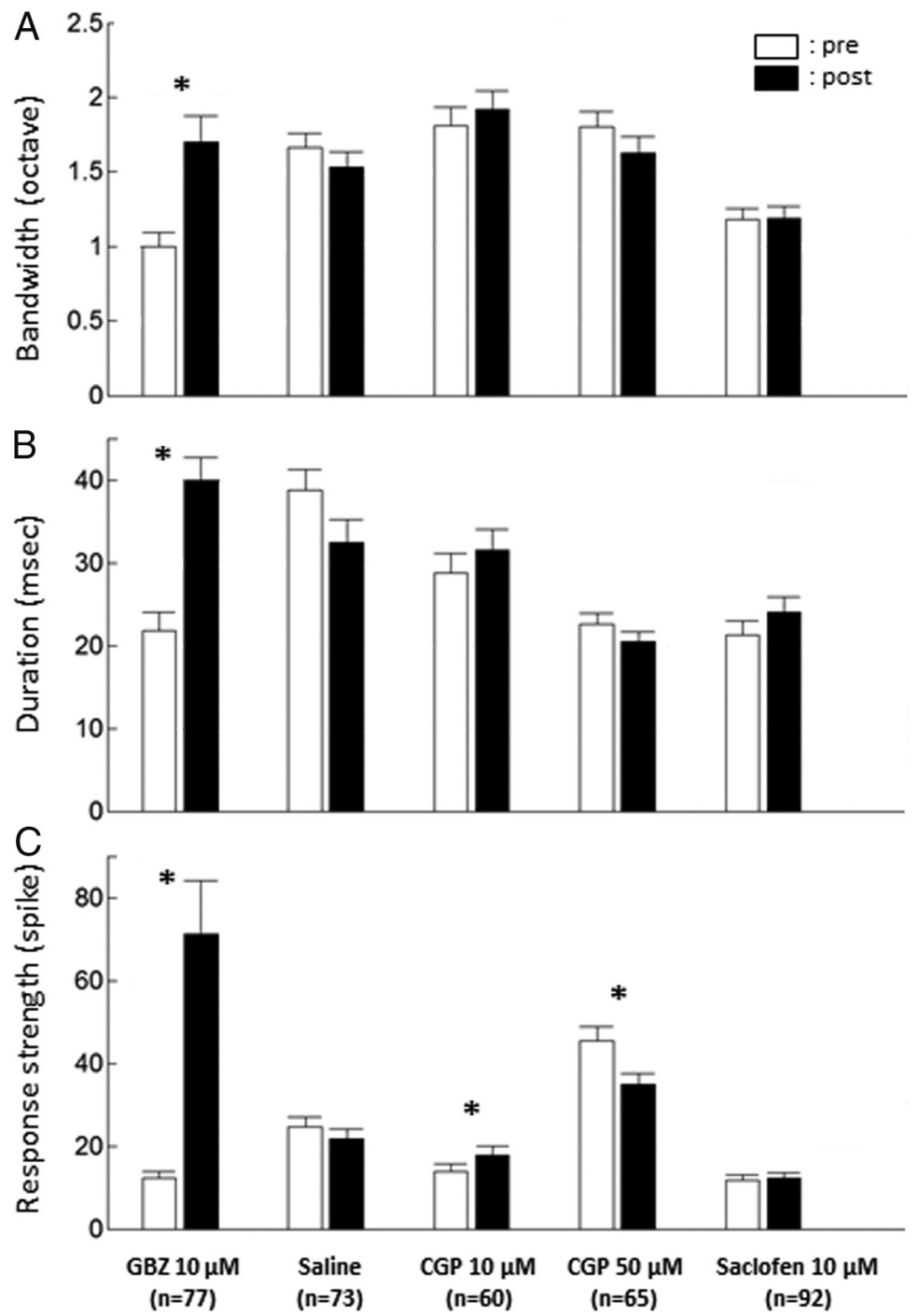

Figure 4. Group data showing the effects of the pharmacological agents on three STRF parameters. The bandwidth $(\boldsymbol{A})$ corresponds to the sum of the width (in octaves) for all significant STRF peaks. The duration $(\boldsymbol{B})$ is the difference between the last and first spikes within a significant STRF peak in milliseconds. The response strength $(\boldsymbol{C})$ is the number of spikes within significant STRF peaks. Note that only GBZ produced a significant increase of these three parameters. Bars represent mean values; error bars represent SE. Black bars, Before application; white bars, immediately after application. ${ }^{*} p<0.0033$, significant paired $t$ test (Bonferroni's correction, 15 tests).

highest intensities $(p<0.001)$ but not at the lowest ones $(\leq 55$ $\mathrm{dB}$ ), suggesting that the tuning bandwidth is less influenced by inhibition close to threshold.

Altogether, these results clearly indicate that application of $\mathrm{GABA}_{\mathrm{A}}$ antagonists expanded the STRF in the spectral and temporal domains. At the concentration used here (up to $50 \mu \mathrm{M}$ for CGP), antagonists of $\mathrm{GABA}_{\mathrm{B}}$ receptors have little or no effects on the STRF parameters. In fact, the changes detected after application of $\mathrm{GABA}_{\mathrm{B}}$ antagonists were in the range of those observed after saline application.

\section{Effects of the GABA antagonists on responses to communication sounds}

The responses to vocalizations were analyzed for the recordings exhibiting at least an evoked firing rate of 1.5 spikes/s or at least a value of CorrCoef of 0.15 (see Materials and Methods). For this subset of recordings ( $n=44$ of 80 recordings), the GBZ effects observed in the STRFs were identical to those described for the whole population (bandwidth, $p<0.002$; response duration, $p<0.0001$; response strength, $p<0.002$ ).

Before drug application, the raster plots revealed the presence of reproducible spike patterns in the responses to vocalizations. For example, in Figure $5 A$, the recordings collected from electrodes 3,4 , $9,10,14$, and 15 displayed reproducible patterns with presentations of a chutter call, whereas the recordings obtained from other electrodes did not. Over the whole population, there was an increase in firing rate during each vocalization relative to spontaneous activity (paired $t$ test between spontaneous and evoked activity for each response, $p<0.0001$ ), but recordings exhibiting clear increases in firing rate during the vocalizations did not always display temporal patterns. There was no systematic difference in terms of firing rate or CorrCoef between the responses to conspecific and heterospecific vocalizations. Some differences were detected (e.g., the CorrCoef was higher for the conspecific compared with the heterospecific purr, $p<0.05$ ), but they could simply result from the fact that the modulation power spectra were not equalized between the two sets of stimuli.

As expected, based on the effects observed in the STRFs, GBZ application increased the responses evoked by vocalizations. Figure $5 B$ shows that this increase reinforced preexisting temporal patterns (electrodes 9, 10, 14, and 15) and also revealed the presence of previously undetectable temporal patterns (electrodes 11-13). As illustrated in Figure 5C, the increase in firing rate obtained after GBZ application was often accompanied by an increase in CorrCoef, whereas CGP ( $\mathrm{GABA}_{\mathrm{B}}$ antagonists) did not increase either the firing rate or the CorrCoef (Fig. 5D).

The group data, based on responses to all vocalizations, confirmed the effects described by these examples. As shown in the scattergrams of Figure 6A, GBZ application promoted large increases in firing rate (presented by the points above the diagonal line). Saline and CGP application induced significant effects, which were much smaller than those triggered by GBZ (Fig. $6 \mathrm{~A}$, inset; GBZ, $8.5 \pm 0.4$ vs $15.1 \pm 0.6$ spike/s, $p<0.0001$; saline, $11.1 \pm 0.6$ vs $13.8 \pm 0.6$ spike/s, $p<0.0001$; CGP at $10 \mu \mathrm{M}, 7.5 \pm$ 0.4 vs $9.2 \pm 0.5$ spike $/ \mathrm{s}, p=0.0002$; CGP at $50 \mu \mathrm{M}, 11.5 \pm 0.5$ vs $10.4 \pm 0.6$ spike/s, $p=0.2$ ).

Similarly, scattergrams representing the effects on the CorrCoef index (Fig. 6B) indicate that only GBZ promoted an increase in trial-to-trial reliability. On average, after GBZ application, the CorrCoef was increased $(0.11 \pm 0.01$ vs $0.18 \pm 0.01$; $p=0.0007)$, whereas it was unchanged after saline application $(0.05 \pm 0.005$ vs $0.04 \pm 0.005 ; p=0.2)$. The CorrCoef was slightly decreased after application of CGP at $10 \mu \mathrm{M}(0.09 \pm 0.007$ vs $0.06 \pm 0.006 ; p<0.0001)$, an effect that was not confirmed when 
A Pre GBZ application

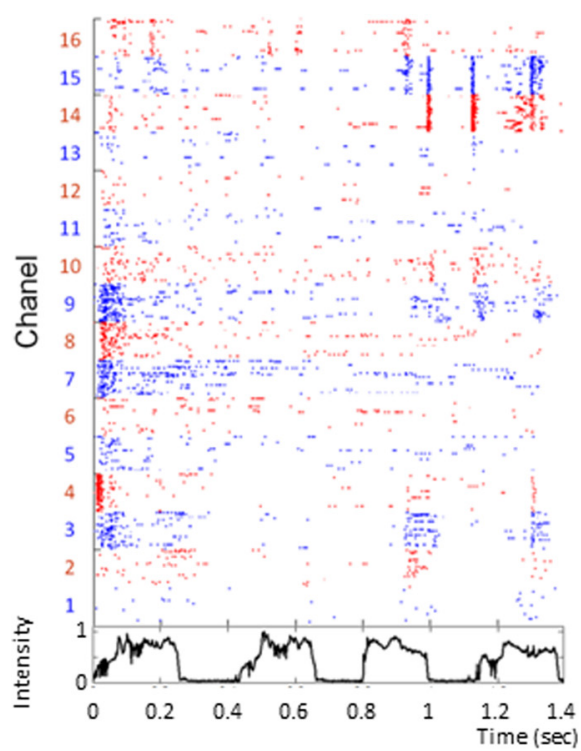

B Post GBZ application

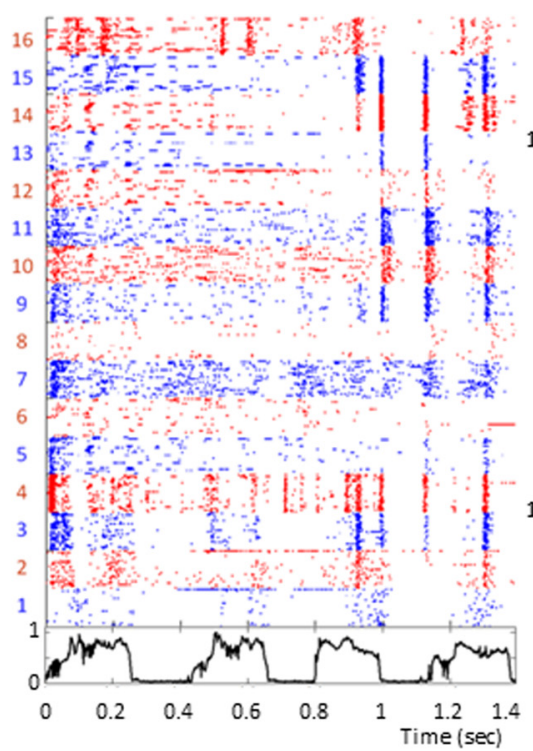

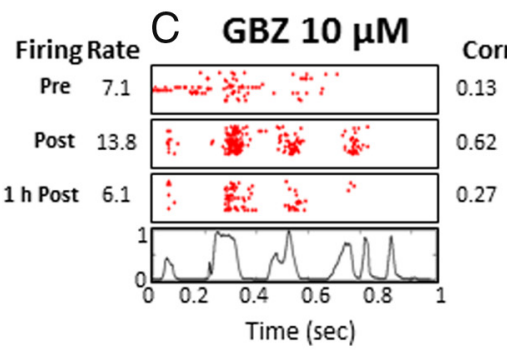

Firing Rate $D \quad$ CGP $50 \mu \mathrm{M}$

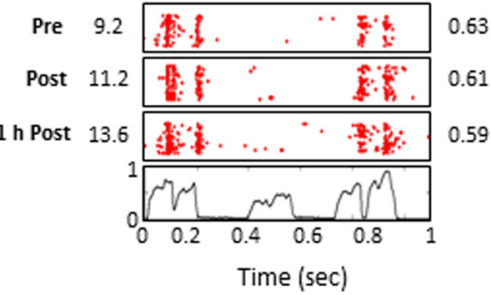

Figure 5. Rasters illustrating the effects of $G A B A_{A}$ or $G A B A_{B}$ antagonist application on responses to vocalizations. Neuronal responses were recorded under 16 electrodes before $G B Z$ application $(\boldsymbol{A})$ and after application $(\boldsymbol{B})$. Each dot represents the emission of an action potential under the electrode labeled on the left. Each line corresponds to the neuronal response to a chutter call, the envelope of which is represented below the raster plot. Each vocalization is presented 20 times, and the raster plots are aligned on the beginning of the stimulus. This representation allows the detection of reproducible spike patterns within cortical responses. To facilitate visualization, the raster color is changed from one electrode to the next. Here, GBZ application increased the responses by reinforcing the preexisting temporal spikes patterns (electrodes 14 and 15) and promoting the emergence of patterns under non-responsive electrodes (electrodes 9 and 11-13). C, Quantification of the effects induced by GBZ application: for this recording, the raster plots represent responses before GBZ application (Pre), immediately after application, (Post) or $1 \mathrm{~h}$ after application ( $1 \mathrm{~h}$ Post). Values of evoked firing rate and temporal reliability coefficient (CorrCoef) are given alongside the figure. Note the simultaneous increase in firing rate and in CorrCoef post-GBZ application. The values returned to control level $1 \mathrm{~h}$ after application. D, Quantification of the effects induced by a $50 \mu \mathrm{m} \mathrm{CGP} \mathrm{application.} \mathrm{Conventions} \mathrm{as} \mathrm{in} \mathrm{C.} \mathrm{Note} \mathrm{the} \mathrm{lack} \mathrm{of} \mathrm{effect} \mathrm{on} \mathrm{the} \mathrm{firing} \mathrm{rate} \mathrm{and} \mathrm{CorrCoef.}$

\section{A Firing rate (spike. $\left.\sec ^{-1}\right)$}
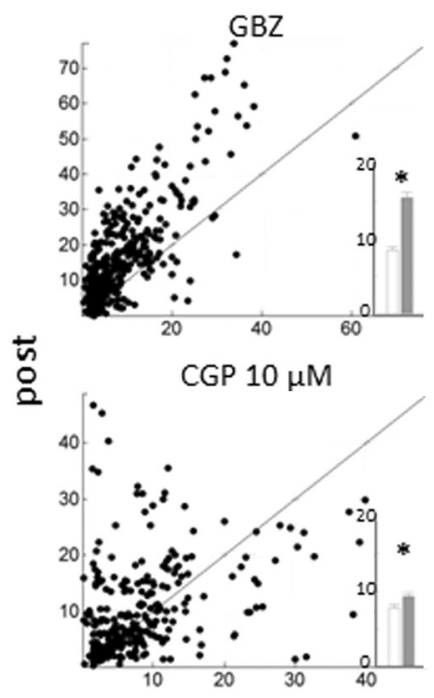

\section{B CorrCoef}
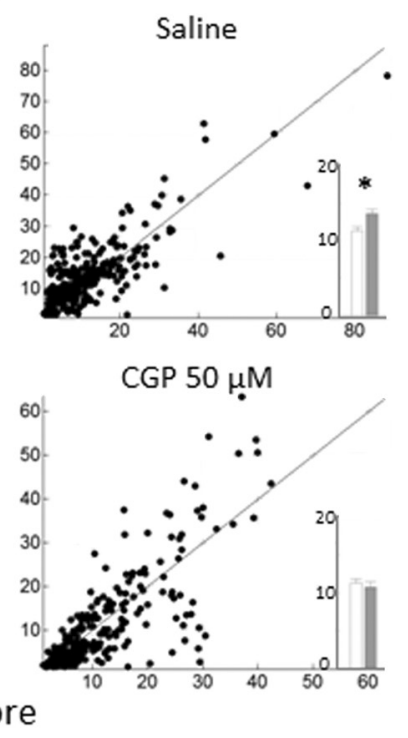

GBZ

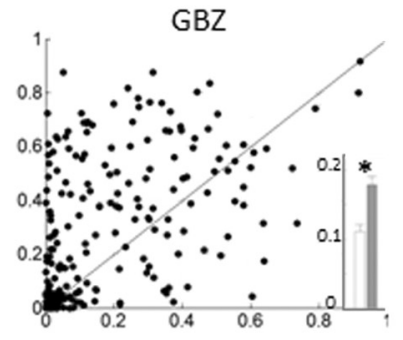

范

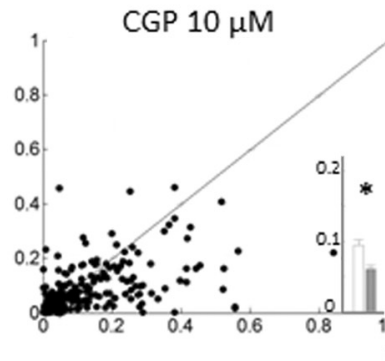

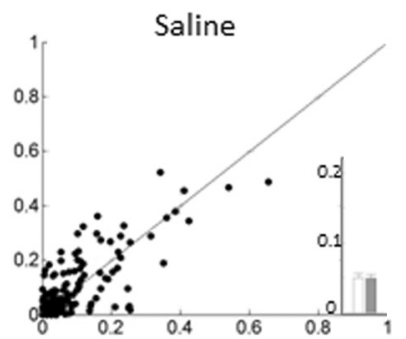

CGP $50 \mu \mathrm{M}$

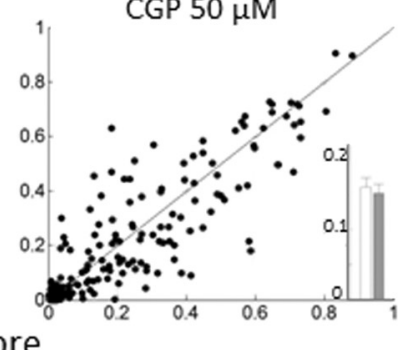

Figure 6. Effects on firing rate and temporal reliability coefficient (CorrCoef) of $\mathrm{GABA}_{A}$ and $\mathrm{GABA}_{B}$ antagonists. All scattergrams show the values obtained at presentation of vocalizations in the control condition (pre) against values obtained immediately after application (post). Scattergrams in $A$ correspond to effects of the different pharmacological agents on the evoked response (evoked minus spontaneous firing rate). Scattergrams in $B$ correspond to effects of pharmacological agents on the temporal reliability coefficient. The insets within each scattergram display the mean \pm SE before (white) and after (gray) drug application. ${ }^{*} p<0.001$. Note the large increase in firing rate and CorrCoef obtained after GBZ application.

a CGP concentration of $50 \mu \mathrm{M}$ was used $(0.16 \pm 0.01$ vs $0.15 \pm$ $0.01 ; p=0.10$ ). Remember that CorrCoeff values above 0.026 are significantly above the chancel level computed from our simulations (see Materials and Methods).

As explained in Materials and Methods, the variability of covariations between pairs of recording sites can also be investi- gated by computing the noise correlations. GBZ application significantly increased noise correlations in the neuronal responses to vocalizations (from $0.31 \pm 0.02$ to $0.45 \pm 0.03 ; p<$ 0.001 ; Fig. 7 ). This increase in noise correlations indicated that, for every pair of recording sites, the covariability of their responses tended to be reduced. This suggests that GBZ tended to 


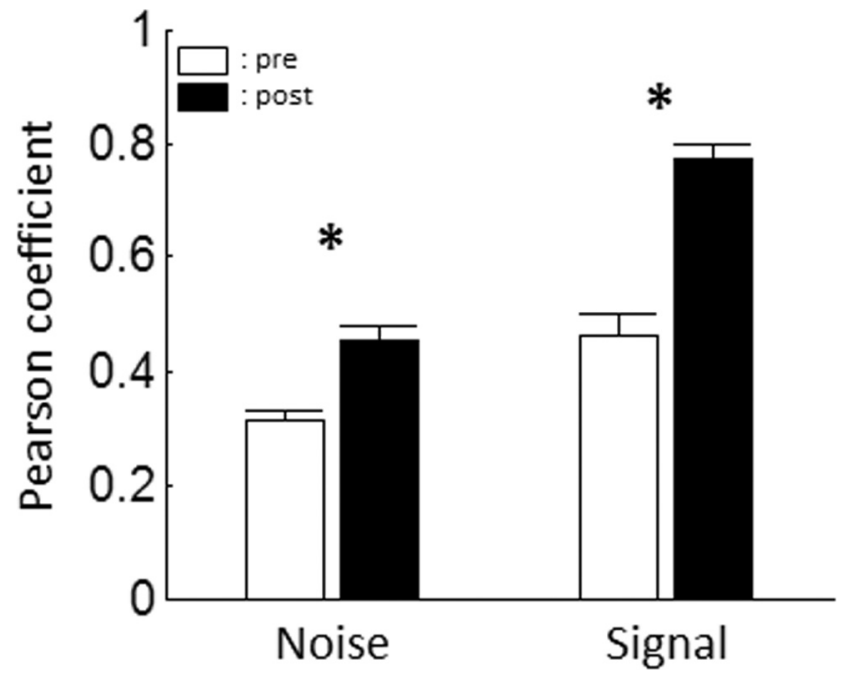

Figure 7. Group data showing the effect of GBZ application on signal and noise correlations. Noise correlations (i.e., the correlation of the firing rate of a pair of recording sites in response to presentations of the same stimulus) and signal correlation (i.e., the correlation between the mean responses of the same pair of recording sites to different stimuli) were computed from the responses of each pair of recording sites responding significantly to vocalizations. Left, Mean noise correlation between pairs of neuronal responses before (white) and after (black) GBZ application. Right, Mean signal correlation between pairs of neurons before and after GBZ application. ${ }^{*} p<0.001$.

increase the strength of a common influence on pairs of recording sites. Interestingly, GBZ not only decreases the individual variability (as shown by the increased CorrCoef) but also makes it more correlated between pairs of recording sites. Note that this result also held true when responses to pure tones were considered (from $0.1 \pm 0.01$ to $0.21 \pm 0.01 ; p<0.001$; data not shown).

Surprisingly, the GBZ induced increase in trial-to-trial reliability was concomitant with an increase of the encoding window as measured from the SAC (10.78 \pm 3.82 vs $20.72 \pm 2.81 \mathrm{~ms} ; p<$ $0.05)$, which was not the case with saline application (14.76 \pm 2.51 vs $12.19 \pm 1.75 \mathrm{~ms} ; p=0.34$ ). This result points out that more complex effects than a simple increase in trial-to-trial reliability may be induced by GBZ.

In fact, from the rasters in Figure $5 B$, it appears that in many cases the strongest phasic excitatory responses were followed by strong suppression of activity potentially induced by cortical inhibition. These periods of inhibition seem to be more pronounced after GBZ applications. To determine whether this was true at the population level, we built averaged PSTHs before and after GBZ application using all the recordings. Figure 8 shows PSTHs for the three vocalizations in which significant responses could be averaged over the largest populations ( $n>20$ recordings). After GBZ application, the periods of strongest responses were followed by periods of more pronounced silence for the whistle and the songbird (Fig $8 A, B$, arrows). However, this effect was not systematic because it did not occur for the heterospecific whistle (Fig. 8C). To determine how general this effect was over the population of recordings and across the different vocalizations, we averaged all the significant peaks of responses. For each PSTH, we first detected significant peaks of responses by a firing rate superior to the spontaneous activity plus four times its SD. This threshold was used to delimit the beginning and ending of each peak. Only peaks of response lasting $>20 \mathrm{~ms}$ and $<80 \mathrm{~ms}$ were taken into account. Averaging all the significant excitatory peaks of responses obtained from these PSTHs (Fig. 8D) revealed that, after GBZ application, the activity tended to fall below the level obtained before the peak of the vocalization, whereas it remained at that level before application. Statistical comparison between the averaged $20 \mathrm{~ms}$ before and after the peak (Fig. 8E) confirmed that GBZ increases the post-peak inhibition (prepeak, 25.3 to 25.1 spikes/s; post-peak, 24.7 to 20.2 spikes $/{ }^{1}$; $p<$ 0.001 ), indicating that applying $\mathrm{GABA}_{\mathrm{A}}$ receptor antagonists can paradoxically reinforce phasic inhibition during natural stimuli.

\section{Investigating the neural code before and after reducing intracortical inhibition}

For each recording, we quantified the estimated MI for nine values of temporal resolution before and after drug application. These values ranged from the shortest vocalization duration (the conspecific whistle, $264 \mathrm{~ms}$ ) to $1 \mathrm{~ms}$. Figure 9 (left) presents the spike trains of two multiunit recordings before and after GBZ application. From these raster plots, it is apparent that GBZ increased the strength of evoked responses but also reinforced temporal organization of responses during the first $264 \mathrm{~ms}$ of vocalizations (left of the dotted line on the rasters; the vocalization duration is represented by the black lines below the rasters). As shown in Figure 9, $A 3$ and B3, when MI was computed for increasing values of temporal resolution, the MI values after GBZ application were systematically higher than those before application. Two variables were extracted from these curves (see Materials and Methods). First, we selected for each recording the MI value obtained for the largest bin size $(264 \mathrm{~ms})$, which is the amount of information carried by the firing rate over this time period $\left(\mathrm{MI}_{\mathrm{FR}}\right)$. Second, we selected the MI value for a temporal resolution of $8 \mathrm{~ms}\left(\mathrm{MI}_{8 \mathrm{~ms}}\right)$ to quantify the amount of information carried by temporal patterns (the $8 \mathrm{~ms}$ resolution was chosen according to Schnupp et al., 2006; Huetz et al., 2009; see Materials and Methods). The values of $\mathrm{MI}_{\mathrm{FR}}$ and $\mathrm{MI}_{8} \mathrm{~ms}$ were compared before and after drug application.

Figure $10 \mathrm{~A}$ shows the effects of pharmacological agents on the MI carried by individual cortical sites, when computed from either firing rate (Fig. 10A1, top, A2) or temporal patterns (Fig. $10 A 1$, bottom, $A 3)$. Figure $10 A 1$ shows the discriminative ability of a cortical site. In the control condition (Pre GBZ), the discriminative ability was low $\left(\mathrm{MI}_{\mathrm{FR}}=0.49\right.$ bits; $\mathrm{MI}_{8 \mathrm{~ms}}=0.45$ bits $)$ but was increased after $\mathrm{GBZ}$ application $\left(\mathrm{MI}_{\mathrm{FR}}=0.75\right.$ bits; $\mathrm{MI}_{8 \mathrm{~ms}}=$ 1.17 bits). On average (Fig 10A2,A3), saline application did not change the value of $\mathrm{MI}_{\mathrm{FR}}$ and the value of $\mathrm{MI}_{8 \mathrm{~ms}}(p>0.5$ and $p>$ 0.6 ; respectively). In contrast, the values of $\mathrm{MI}_{\mathrm{FR}}$ and $\mathrm{MI}_{8 \mathrm{~ms}}$ were significantly increased after GBZ application $(p<0.0001$ in both cases; Fig. 10A2,A3). The increase in $\mathrm{MI}_{8 \mathrm{~ms}}$ was not attributable to the increase in firing rate between pre-GBZ and post-GBZ application because an increase in $\mathrm{MI}_{8 \mathrm{~ms}}$ value was still observed when using the normalization procedure (the pre and post responses were normalized because their firing rate were identical: without normalization, $\mathrm{MI}_{8 \mathrm{~ms}}=0.727$ bits; with normalization, $\mathrm{MI}_{8 \mathrm{~ms}}=0.719$ bits; for details, see Materials and Methods). These increases were not observed with saclofen and CGP. These results indicate that GBZ application increased the information carried by firing rate and spike patterns. Obviously, MI computed at a single cortical site $\left(\mathrm{MI}_{\text {individual }}\right)$ provides only a partial reflection of the encoding ability of the ACx. To gain more insights into how reducing intracortical inhibition affects the coding ability of the whole $\mathrm{ACx}$, we computed the MI derived from simultaneously recorded cortical sites $\left(\mathrm{MI}_{\text {population; see Materials and }}\right.$ Methods). Responsive sites were selected with two criteria: (1) significant responses to vocalization and (2) MI estimate that is significantly above the bias (see Materials and Methods). Confusion matrices obtained from a set of simultaneous recordings 

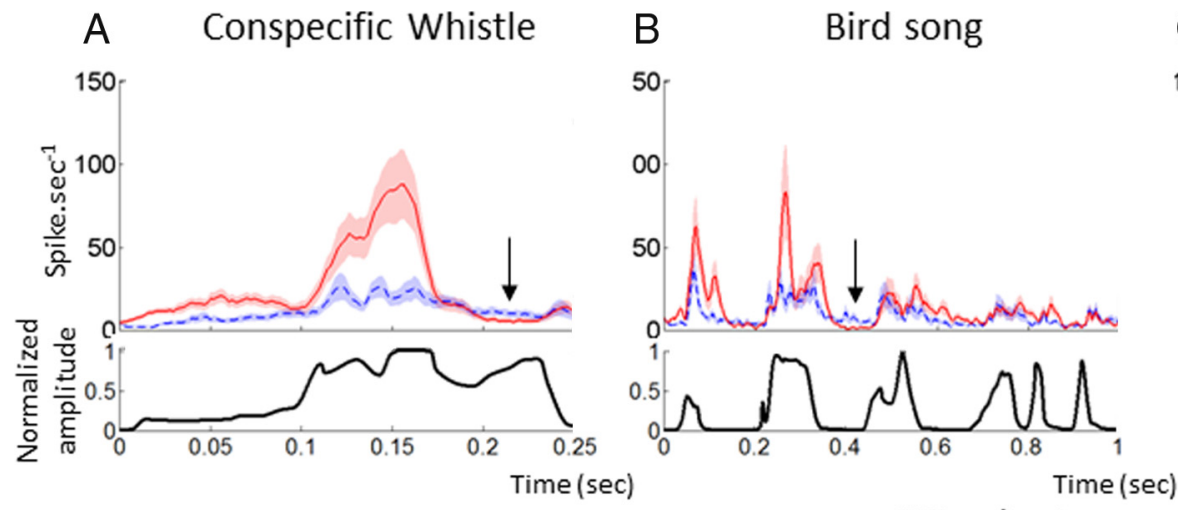

----- : pre GBZ application
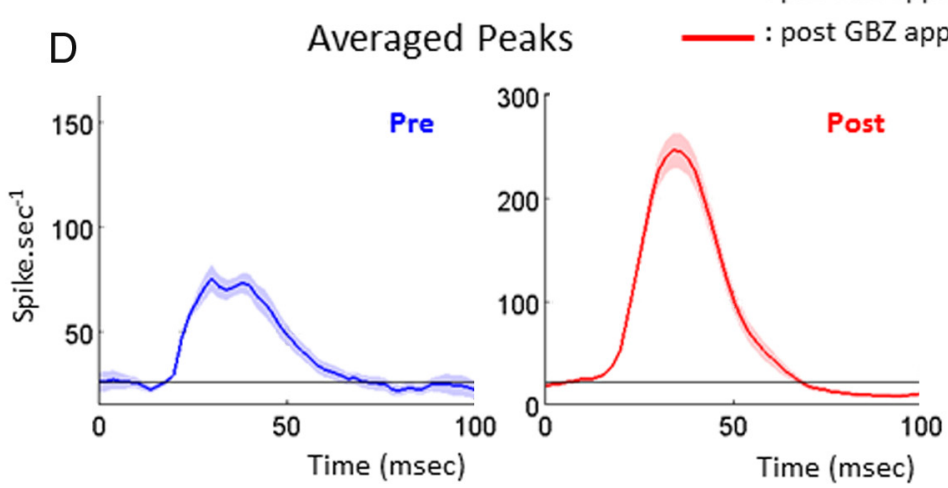

C Heterospecific Whistle

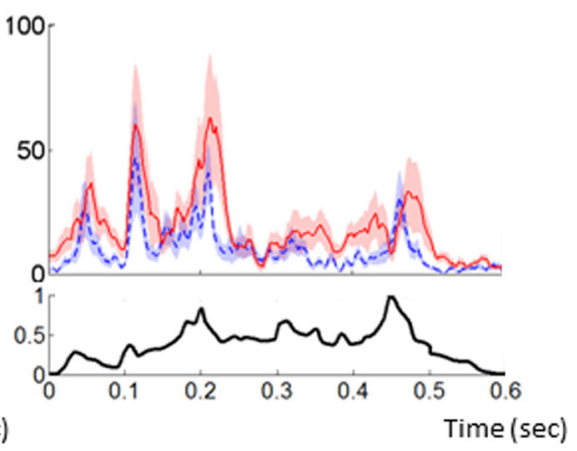

E Firing rate before and after peak

Figure 8. GBZ effects on the averaged PSTH in response to three vocalizations. Average PSTHs of all recordings showing significant responses to the conspecific whistle ( $\boldsymbol{A}$ ), the heterospecific whistle $(\boldsymbol{B})$, and the bird song ( $\boldsymbol{C}$ are displayed before (blue dotted line) and after (red shaded line) GBZ application. The envelope of the vocalization is represented below each PSTH. The black arrows indicate periods of reinforced inhibition after GBZ application. In $\boldsymbol{D}$, all the significant peaks (superior to baseline +4 times the baseline SD) before and after GBZ application (blue and red curves) were averaged. Black lines indicate the baseline level before the peak. Note that, after GBZ application, the post-peak activity felt below the level of pre-peak activity, whereas it returned at the same level before application. The average firing rate over 20 ms before and 20 ms after the peak $(\boldsymbol{E})$ showed a significant decrease in activity after GBZ application ( ${ }^{*} p<0.001$, unpaired $t$ test). Altogether, these results suggest that $\mathrm{GBZ}$ reinforced the post-peak inhibition.

(Fig. 10B1) illustrate that the discriminative ability of a population is accurate, although false attributions could happen. Usually, confusion occurred between stimuli with similar acoustic parameters (for example, purr and dove call; Fig. 10B1, Pre GBZ). Again, the $\mathrm{MI}_{\text {population }}$ computed with temporal patterns was higher than the $\mathrm{MI}_{\text {population }}$ computed with firing rate. The $\mathrm{MI}_{\text {population }}$ computed from firing rate was not affected by saline application or by any of the agonists used in our study, including GBZ (Fig. 10B2, $p>0.1$ ). Surprisingly, this result was the same even when $\mathrm{MI}_{\text {population }}$ was computed from temporal patterns (Fig. 10B3, $p>0.1$ ). Thus, the MI computed from ensemble recordings is unaffected by GBZ application, whereas MIs computed from single cortical site of the same ensemble are increased. This paradoxical result suggests the following hypothesis: reducing inhibition locally increased the information measured at cortical sites but at the same time left unaffected the information carried by large ensemble recordings. Logically, this should imply that the redundancy between cortical sites was increased.

To directly assess this hypothesis, the $\mathrm{MI}_{\text {population }}$ was quantified for various sizes of recording ensembles (from 2 to 16 sites) and compared with the sum of the individual MIs of the same ensemble (see Materials and Methods). Figure 11A displays the evolution of the $\mathrm{MI}_{\text {population }}$ for one recording ensemble as a function of the size of this ensemble, before and after GBZ application. For small sizes of recording ensembles $(n<5)$, the information was not redundant, but for larger sizes, the information carried by each site started to become redundant (as indicated by the asymptotic shape of the two curves on Fig. 11A). Figure $11 B$ shows the sum of $\mathrm{MI}_{\text {individual }}$ as a function of the number of sites considered, before and after GBZ application. As expected, the $\mathrm{MI}_{\text {population }}$ increased linearly with the number of cortical sites and always remained higher after GBZ application than before. Finally, Figure $11 C$ shows the redundancy, quantified by the $\mathrm{P}_{\text {ensemble }}$ (see Materials and Methods) as a function of the number of sites. Both before and after GBZ application, the $\mathrm{P}_{\text {ensemble }}$ is negative and inversely proportional to the amount of sites considered, indicating that the responses at each cortical site were redundant. The difference between the red and blue curves points out the difference in redundancy before and after GBZ application. With this particular example, the difference was negative, implying that the information carried by this set of cortical sites was more redundant after GBZ application. The difference between the $\mathrm{P}_{\text {ensemble }}$ before and after application was computed for all the recording ensembles and all tested drugs (Fig. 11D). GBZ application induced a clear increase in redundancy of the responses, as indicated by the fact that all but one curves were negative. On the contrary, saclofen and CGP application did not induce any clear effect on redundancy.

Potentially, redundancy could also be investigated through the analysis of signal correlation. This analysis showed that the mean Pearson's coefficient between the mean responses to vocalizations of neuron pairs was significantly increased by GBZ application (from $0.46 \pm 0.04$ to $0.77 \pm 0.02 ; p<0.001 ;$ Fig. 7 ). This increase in signal correlation indicated that every pair of recording sites tended to respond similarly to the same stimuli. This result confirmed that GBZ application induced a homogenization of the neuron responses, thus increasing their redundancy. Note that Pearson's coefficient can only be calculated for two- 

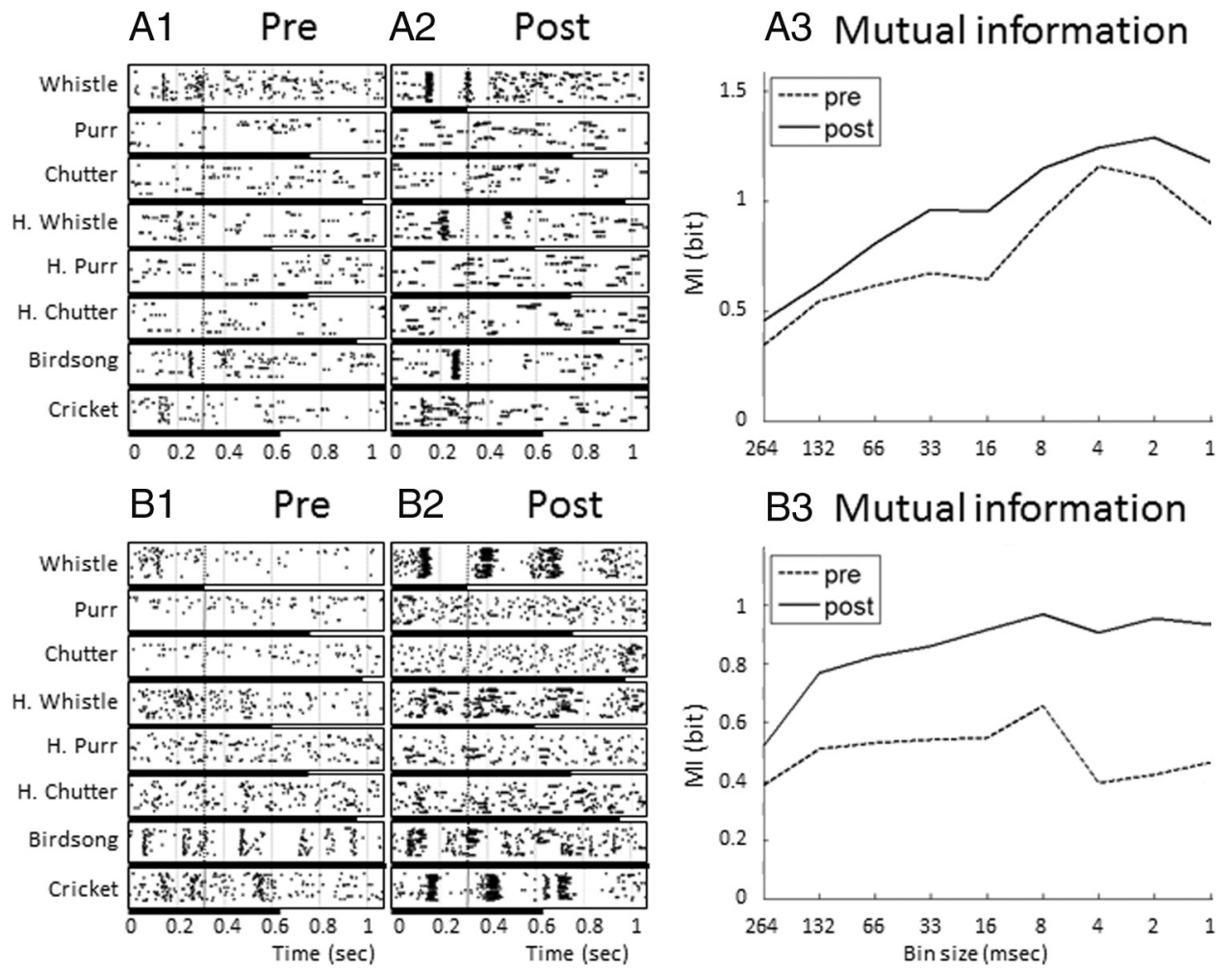

\section{B3 Mutual information}

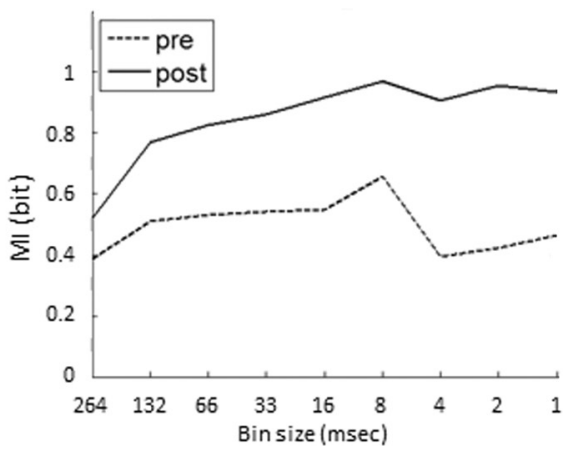

Figure 9. Rasters of neuronal responses to the whole set of eight vocalizations and values of MI calculated from these responses with different temporal resolutions. The responses to the eight vocalizations for two different recording sites are represented before $(\boldsymbol{A 1}, \boldsymbol{B} \mathbf{1})$ and after $(\boldsymbol{A 2}, \boldsymbol{B} 2) \mathrm{GBZ}$ application. The dotted vertical line represents the duration of the shortest vocalization (Whistle, $264 \mathrm{~ms}$ ), which was used to compute the MI. The black bars below the raster plots represents the duration of each vocalization. The MI values were computed from these responses before (A3-B3,

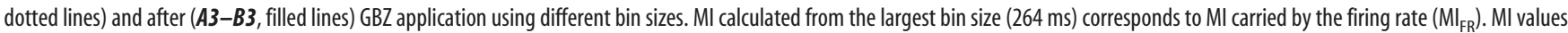
obtained with smaller bin sizes correspond to the MI carried by progressively more precise temporal patterns. On average (but not systematically), the highest values of MI were obtained for a $8 \mathrm{~ms}$ bin size. Note that GBZ application increased the MI values regardless of the bin size.

dimensional sets of data, hence preventing the computation of signal correlation between more than two recording sites. The signal correlation between responses to pure tones was also increased by GBZ application (from $0.2 \pm 0.02$ to $0.39 \pm 0.03 ; p<$ 0.001 ; data not shown). This last result is not surprising given the fact that GBZ increased the bandwidth of the STRFs.

Together, these analyses demonstrate that decreasing the level of $\mathrm{GABA}_{\mathrm{A}}$-mediated inhibition increases the information carried by the spike trains for individual cortical sites but also increased cortical response redundancy.

\section{Discussion}

Here, we show that, when a partial blockage of $\mathrm{GABA}_{\mathrm{A}}$ receptors is efficient enough to expand cortical STRFs, the responses of $A C x$ neurons to communication sounds are increased and temporally more reliable. Consequently, the discrimination performance of each individual cortical site (indexed by the MI) is enhanced in terms of both firing rate and temporal spike patterns. However, under these conditions of reduced inhibition, the MI computed at the population level (i.e., when groups of 2-16 cortical sites are considered) is unaffected, and we propose that this is likely attributable to an increased redundancy of neural responses after GBZ application. These results suggest that, in normal conditions, cortical inhibition contribute to decreased cortical responses redundancy.

\section{Methodological considerations}

Topical application has been used previously in various cortical (Eder et al., 1997; Jones and Barth, 2002; Yu et al., 2008) and cerebellar (Caesar et al., 2008; Wang et al., 2009) areas because it presents several advantages. At variance with iontophoretic application, which allows application of a drug to a single location, topical application exerts an effect on the entire cortical network converging onto the recorded neurons. The drug concentration that actually reached the cortical neurons was unknown (as it is with iontophoretic application) but was certainly much lower than $10 \mu \mathrm{m}$ given the short pulse application that we used. In our conditions, it is likely that all cortical layers were affected by the drug application as indicated by the recordings obtained simultaneously at different depths with a 16-channel silicon probe (Fig. 1). Special care was taken to ensure that blocking $\mathrm{GABA}_{\mathrm{A}}$ receptors did not trigger pathological activity: the low drug concentration and the short period of drug application allowed modulation of cortical inhibition without any sign of epileptiform activity. In fact, we first determined (in pilot experiments; see Materials and Methods) the concentration/duration of GBZ application that triggered epileptic activities (12 min application at $20 \mu \mathrm{M}$ ) and reduced the concentration/duration to a level that did not trigger epileptic activity (4 min application at $10 \mu \mathrm{M}$ ).

Obviously, this technique presents pitfalls because applying drugs directly on the cortical surface can produce mechanical instability during electrophysiological recordings. This might explain why saline application led to non-negligible changes in firing rate (relative to control: $20 \%$ in spontaneous activity; $11 \%$ in evoked activity). Also, in contrast with iontophoretic application (Manunta and Edeline, 1997, 1998), it was not always possible here to observe a recovery after GBZ application: when the recordings were stable over long time periods, the effects were often 


\section{A Individual MI}

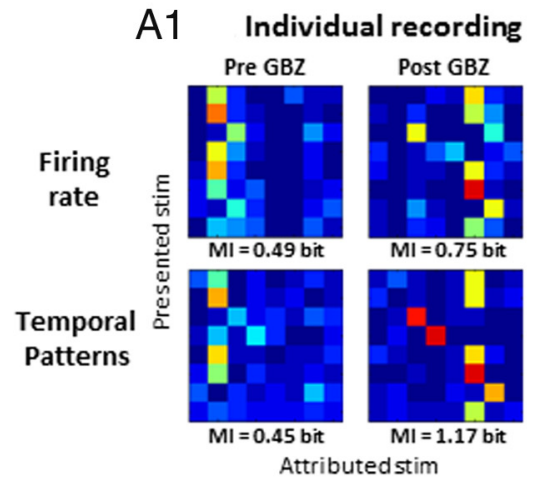

B Populational MI

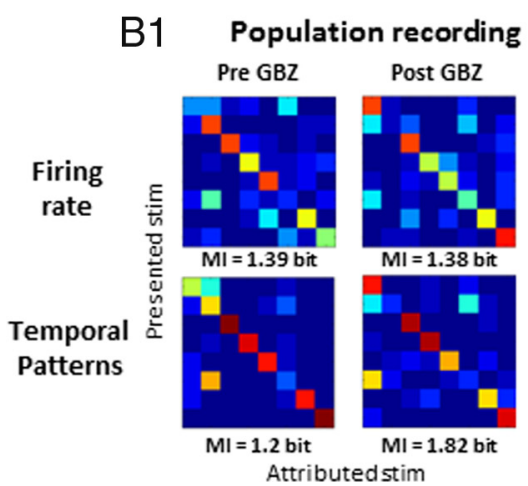

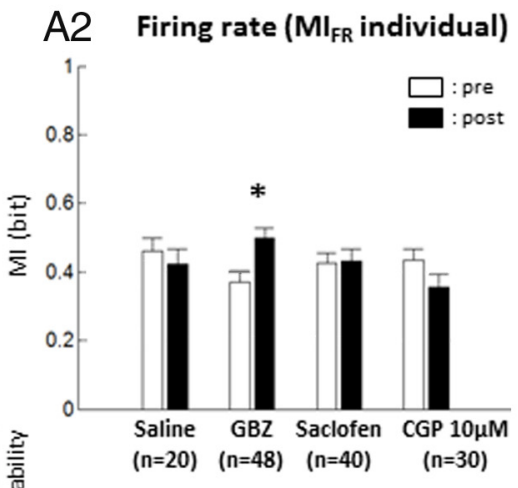

A3 Temporal Patterns $\left(\mathrm{MI}_{8 \mathrm{~ms}}\right.$ individual)

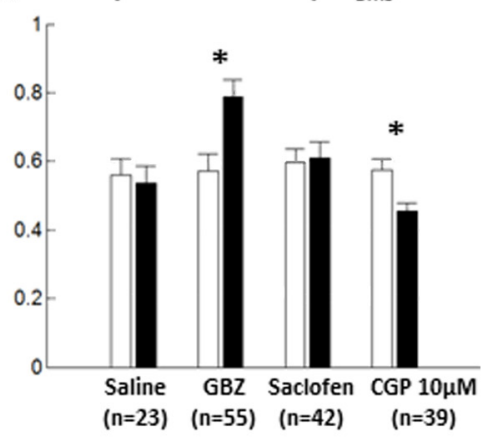

Figure 10. MI values computed from responses to vocalizations before and after drug application. $\boldsymbol{A}, \mathrm{MI}_{\mathrm{I}}$ computed from individual recordings ( $\mathrm{Ml}$ individual). $\boldsymbol{A}$ 1, Confusion matrices obtained by comparing the distance between each spike train and the mean response of each class of stimulus (see Materials and Methods). Those matrices were computed from either firing rate (top) or temporal patterns (bottom), before and after GBZ application. In this example, in both cases, GBZ application increased the MI computed from these matrices. Averaged individual MI computed from firing rate (A2) was significantly increased only after GBZ application. Averaged individual MI computed from temporal patterns ( $A 3$ ) also revealed a significant positive effect of GBZ on MI. Application of CGP at $10 \mu \mathrm{m}$ induced a significant decrease of MI. $B$, Ml computed from simultaneous recordings ( $\mathrm{MI}_{\text {population }}$ ). The spike trains obtained from simultaneous recordings were concatenated and considered as a unique response (see Materials and Methods). From that response, confusion matrices could be computed based on firing rate or temporal patterns (B1). $0 \mathrm{n}$ this individual example, GBZ application did not change the MI computed from the firing rate confusion matrix. The averaged population MI was not significantly affected by the pharmacological agents used in our study, when it was computed from either firing rate $(\boldsymbol{B} 2)$ or temporal patterns $(\boldsymbol{B} 3) .{ }^{*} p<0.01$.

present up to $1 \mathrm{~h}$ after application (for an example of lasting effects, see Fig. $3 A$; for a 1 h post-recovery, see Fig. $5 C$ ). Despite these limitations, the results obtained on the STRF parameters correspond to what should be expected based on the known action of $\mathrm{GABA}_{\mathrm{A}}$ receptor antagonists on cortical neurons.

Caution must be exerted in the interpretation of our findings because multiunit activity was recorded in our experiments and individual neurons were not considered. As a consequence, the MI evaluated at the level of a single cortical site is already the reflection of a local computation performed by a small population of individual neurons. More importantly, the redundancy was computed between small groups of neurons located at various distances from each other on the tonotopic map. At the level of the tonotopic map, reducing cortical inhibition did not influence the population MI but increased the information redundancy. At the level of a single cortical site, MI was increased, but it cannot be assessed whether the redundancy between individual neurons was unaffected, increased, or decreased. Clearly, an additional level of analysis is lacking for complete understanding of how different cell types contribute to increase the local $\mathrm{MI}$ in a small cortical column when inhibition is attenuated. In the following discussion, we should keep in mind that the "local" effects discussed here are at the level of a single cortical site but they might stem from heterogeneous effects at the level of the individual neurons.
Comparison with studies describing the effects of GABA antagonists on $\mathrm{ACx}$ tuning curves

It has long been proposed that GABAergic inhibition sculpts ACX receptive fields (for review, see Suga, 1995; Wehr and Metherate, 2011; Yuan et al., 2011). The concept of lateral inhibition was initially promoted by the two-tone suppression (or forward masking) protocol (Brosch and Schreiner, 1997), but direct evidence only emerged when it was shown that iontophoretic application of bicuculline expands the frequency tuning curves of ACx neurons (Wang et al., 2000, 2002; but see Kurt et al., 2006). In contrast, whole-cell recordings (Wehr and Zador, 2003, 2005; Tan et al., 2004) pointed out the co-tuning of excitation and inhibition converging onto cortical cells and did not reveal a broader tuning of inhibitory currents (but see Wu et al., 2008 for opposite results). In the temporal domain, it was shown that GBZ application induced deterioration of phase-locking to high modulation frequencies (Kurt et al., 2006). With application of $\mathrm{GABA}_{\mathrm{A}}$ antagonist over the entire cortical map (which reduced the activity of the entire inhibitory network converging onto the recorded cells), we report here a concomitant bandwidth and duration expansion of STRFs, suggesting that $\mathrm{GABA}_{\mathrm{A}}$ receptors influence both spectral and temporal selectivity of $\mathrm{ACx}$ neurons.

The lack of effects of $\mathrm{GABA}_{\mathrm{B}}$ antagonists is surprising given that in vitro studies have documented the presence of $\mathrm{GABA}_{\mathrm{B}}$ 


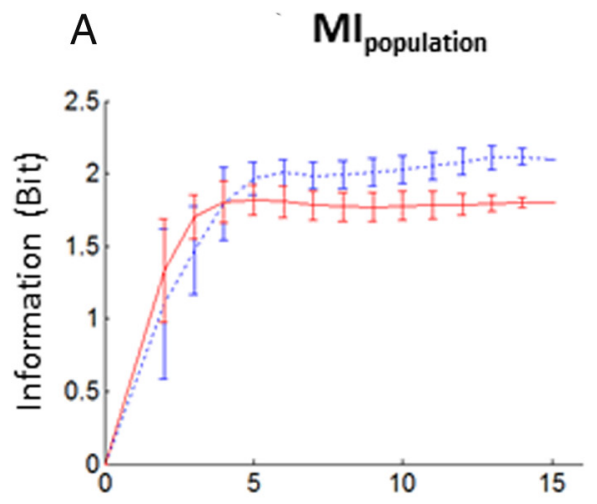

B

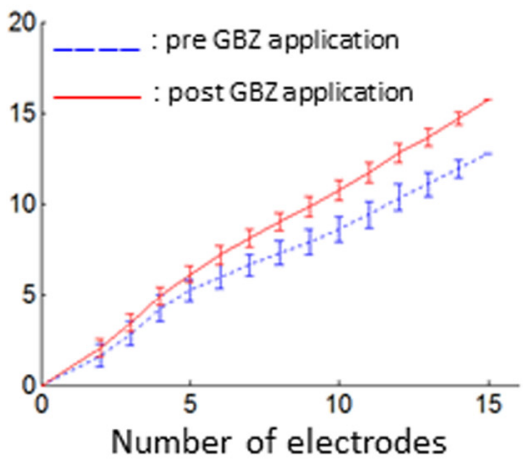

C Redundancy $\left(\mathbf{P}_{\text {ensemble }}\right)$

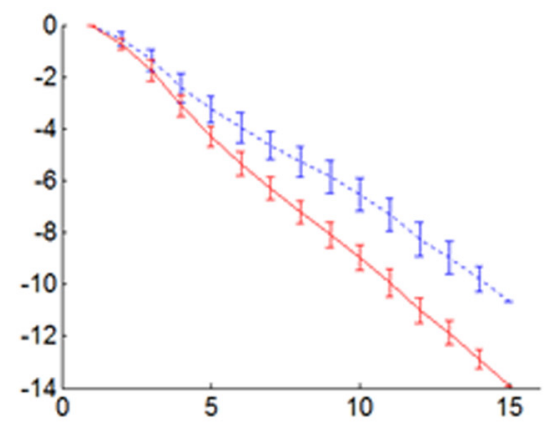

D Difference between post and pre redundancy
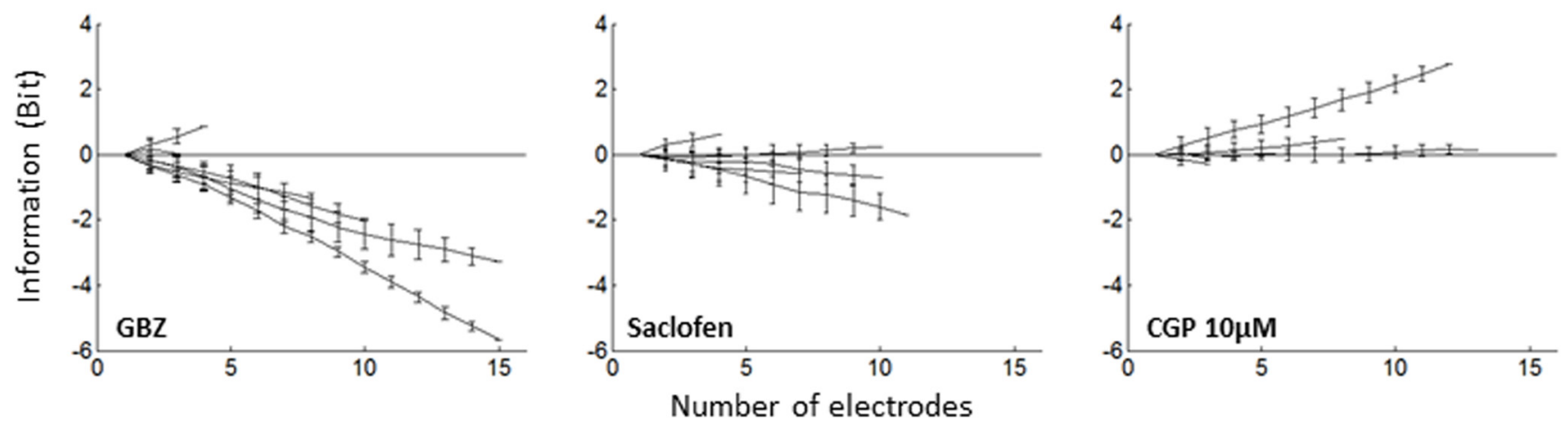

Figure 11. Redundancy in simultaneously recorded neuronal responses. $A$, Example of population $\mathrm{Ml}$ for a set of 16 simultaneous recordings. $\mathrm{MI}_{\text {population }}$ was plotted as a function of the number of recordings used for the computation. The $\mathrm{MI}_{\text {population }}$ computed before (blue dotted line) and after (red solid line) GBZ application is displayed. Note that the information contained in simultaneous neuronal responses increased when the number of considered cortical sites was low ( $n<5$ electrodes) and stabilized when more cortical sites were considered $(n>5)$. $\boldsymbol{B}$, To compute redundancy, the $\mathrm{MI}_{\text {population }}$ was compared with the sum of the $\mathrm{MI}_{\text {individual. }}$. In this example, the sum of $\mathrm{MI}_{\text {individual }}$ increased linearly with the number of electrodes considered. GBZ application induced a general increase in $\mathrm{MI}_{\text {individual. }}$ C, The $\mathrm{P}_{\text {ensemble }}$ of this example was computed as a function of the number of recordings (see Materials and Methods). Here, the $P_{\text {ensemble }}$ is negative, indicating that neuronal responses were redundant. Note that the $P_{\text {ensemble }}$ after $G B Z$ application is inferior to the $P_{\text {ensemble }}$ before application, indicating an increase in redundancy between the two conditions. $\boldsymbol{D}$, The three panels show the difference between $P_{\text {ensemble }}$ after drug application and before drug application for GBZ, saclofen, and CGP applications. Each line corresponds to a different recording ensemble. GBZ application increased redundancy, whereas saclofen and CGP application affected redundancy to a lesser extent.

currents on ACx neurons when activating cortical or thalamic inputs (Cox et al., 1992; Metherate and Ashe, 1994; Hefti and Smith, 2000; Cruikshank et al., 2002; Wehr and Zador, 2005). However, it is possible that $\mathrm{GABA}_{\mathrm{B}}$-mediated inhibition has a time constant that is too slow (160-170 $\mathrm{ms}$ in the study by Cox et al., 1992) and an amplitude that is too low $(4-5 \mathrm{mV})$ to influence the interplay between fast EPSPs and fast IPSPs underlying the short-latency responses of ACx neurons. It might be argued that the concentration used here (up to $50 \mu \mathrm{M}$ ) is not sufficient to modulate the strength and temporal reliability of auditory responses. However, (1) much lower concentrations (50 nM to 1 $\mu \mathrm{M}$ ) were used in vitro to antagonize $\mathrm{GABA}_{\mathrm{B}}$ responses (Bessaiih et al., 2006; Mann et al., 2009) and (2) no effect on laminar current source density profiles was observed with a higher concentration (6 $\mathrm{mm})$ of SCH50911 $[(2 S)(+) 5,5$-dimethyl-2morpholineacetic acid], another $\mathrm{GABA}_{\mathrm{B}}$ antagonist (Happel et al., 2010).

\section{Influence of $\mathrm{GABA}_{\mathrm{A}}$-mediated inhibition on responses to vocalizations}

Very few studies have tried to modulate cortical inhibition with presentation of communication sounds. In the zebra finch HVC nucleus, Rosen and Mooney (2003) disrupted either GIRKmediated inhibition or $\mathrm{GABA}_{\mathrm{A}}$ inhibition intracellularly while quantifying the response to the bird's own song. Surprisingly, temporal spike patterns were suppressed by neither $\mathrm{GABA}_{\mathrm{A}}$ nor $\mathrm{GABA}_{\mathrm{B}}$ blockers. In the functional analogous of non-primary $\mathrm{ACx}$ (the NCM nucleus) of birds a blockade of $\mathrm{GABA}_{\mathrm{A}}$ receptors systematically increased the phasic components of responses to conspecific songs (Pinaud et al., 2008). Similar effects were detected in our study: phasic responses were reinforced without promoting the emergence of tonic responses (Figs. $5 B, C, 8$ ). Oddly, facilitation of phasic responses observed in the NCM occurred without modifications of frequency tuning (Pinaud et al., 2008), whereas the effects reported here in the cortical STRFs are in good agreement with the response modifications to communication sounds. By reducing the level of tonic inhibition, GBZ allowed the expression of subthreshold inputs at the borders of the receptive field leading to broader STRFs. This reduced tonic inhibition also allowed expression of subthreshold inputs in response to vocalizations, which can explain the emergence of new phasic peaks in the responses obtained after GBZ application (Fig. $5 B, C$ ). In addition, strong phasic responses were often followed by prolonged periods of silence, as if the stronger excitatory responses were followed by stronger postexcitation inhibitions (Figs. 8, 9). As depicted in Figure 12, A1 and B1, this can result from the fact that inhibitory neurons are also more excitable after GBZ application (the reduction of tonic inhibition 
also affects these cells). Thus, the result of our experiment opposed our initial predictions. Initially, two reasons led us to suspect that blocking $\mathrm{GABA}_{\mathrm{A}}$ inhibition could impair the temporal precision of neuronal responses. First, disrupting the precise timing of IPSPs and EPSPs converging on a given cell should promote non-reproducible temporal patterns and then lead to a loss of information contained in the temporal patterns. Second, reducing the level of tonic inhibition should increase spontaneous activity, which could also disorganize the temporal patterns by random insertion of spikes in evoked responses. However, these two effects were totally surpassed by a third one, namely by the reinforcement of the feedforward inhibition occurring after each excitatory input from the thalamus. As a consequence, after a salient acoustic event triggering a thalamic volley, the cortex responded with larger excitatory responses followed by a silent period until a new thalamic volley_activated by another acoustic event-triggered the new phasic cortical response. Compared with the control condition, the periods of strong activation followed by silent periods led to a higher spike-timing reliability. Because the exact timing of the sequence of strong activation/ inhibition depends on the vocalization acoustic features, the partial blockage of $\mathrm{GABA}_{\mathrm{A}}$ receptors reinforced the differences between spike patterns elicited by different vocalizations at each cortical site. Thus, at a given cortical site, a partial blockage of intracortical inhibition led to higher levels of information carried by each neuron, simply by reinforcing the within-stimulus similarity (spike-timing reliability) and the between-stimuli differences (temporal response patterns).

Role of inhibition in population coding Partial removal of intracortical inhibition that enhances information contained in spike trains of cortical neurons is a counterintuitive result. However, when groups of simultaneously recorded cortical sites were considered, the population information was not increased by partial blockage of inhibition. In fact, we have to keep in mind that, compared with neurons of subcortical relays, ACx neurons have difficulty in providing an accurate description of the rapidly fluctuating features of communication sounds (Joris et al., 2004; but see Elhilali et al., 2004; Huetz et al., 2011; for review, see Gaucher et al., 2013). Attenuating intracortical inhibition tends to promote a regimen of activity that is mostly controlled by thalamic inputs and might favor responses that are a closer reflection of the stimulus acoustic characteristics than in control situations. Thus, at presentation of a given vocalization, the redundancy between cortical sites is increased because many cortical sites provide similar response pro-

\section{A Control}

B1. Circuit
A1. Circuit
A2. STRF
A3. Responses to vocalizations

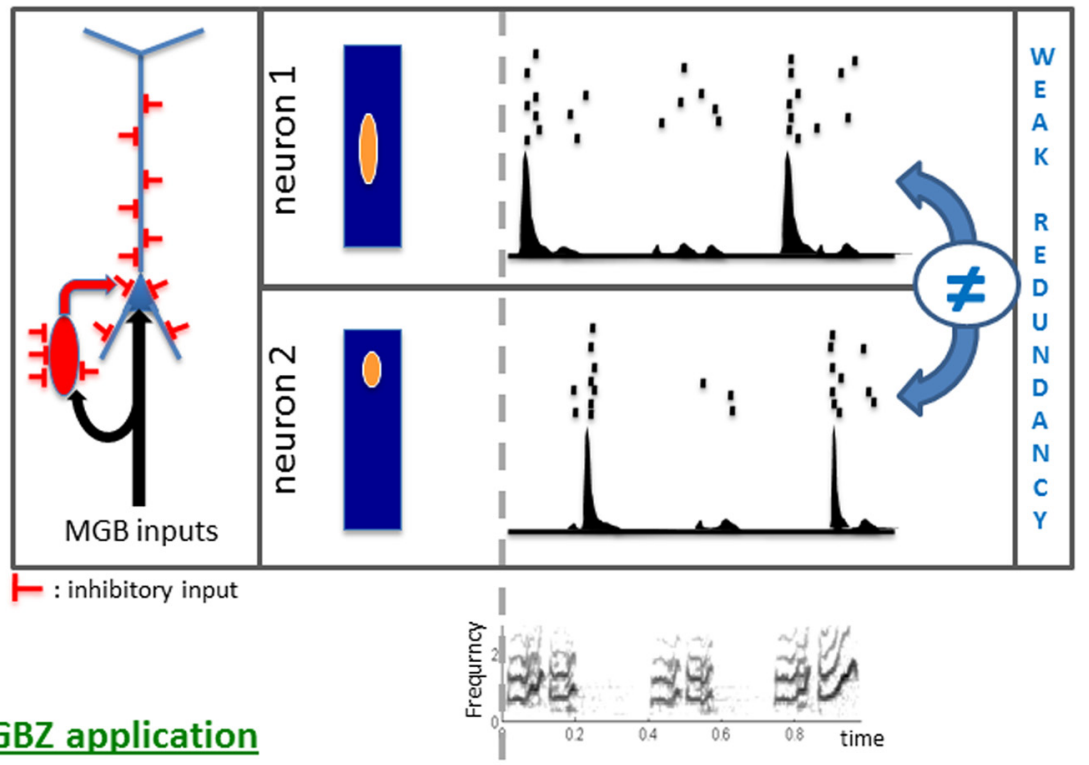

B2. STRF

B3. Responses to vocalizations

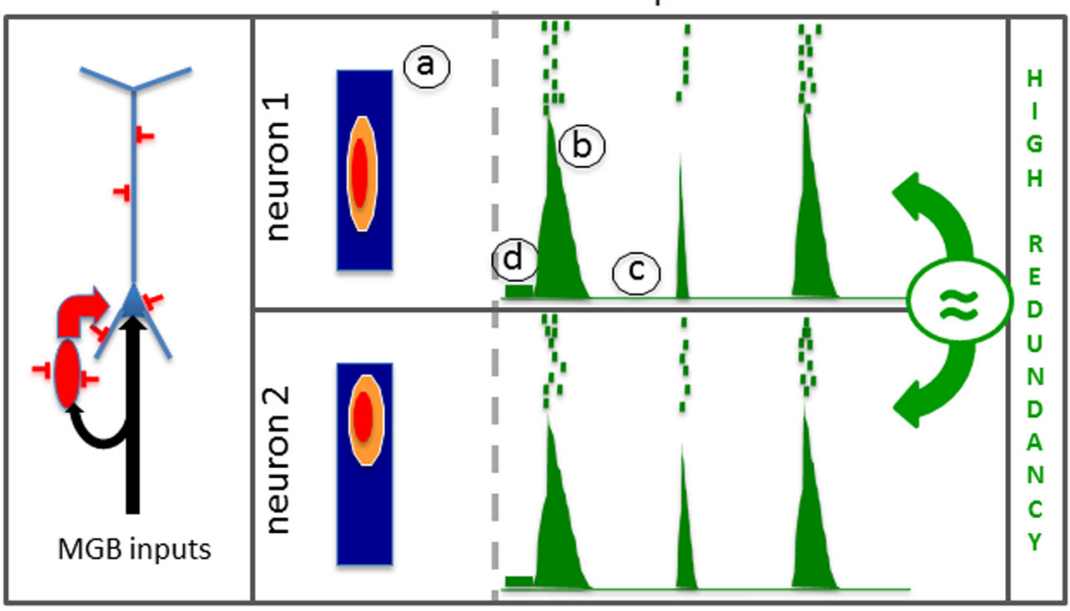

Figure 12. Putative model of $G B Z$ effects on cortical processing. $A$, In the control condition, auditory inputs from the medial geniculate body (MGB; black arrows in A1) reach cortical pyramidal neurons (blue cell) and inhibitory interneurons (red cell), thus providing a phasic excitatory input followed by a phasic inhibition (feedforward inhibition). Both pyramidal cells and inhibitory interneurons also receive tonic inhibitory inputs from local inhibitory networks. The interplay between phasic excitation, phasic inhibition, and tonic inhibition determines the firing patterns of the pyramidal cell, which likely correspond to the recorded neuronal response in our experiments. For a typical recording with a significant STRF $(\boldsymbol{A} 2)$, phasic responses were regularly observed at several time points during the vocalizations (see raster and PSTH in $A 3$ ). $\boldsymbol{B}$, Topical application of GBZ leads to a partial release of inhibitory inputs reaching both the pyramidal cell and the interneuron (schematized here by a reduction of the number of inhibitory inputs; $\boldsymbol{B}$ 1). This reduced inhibition promotes a higher excitability and increased the neuronal response to medial geniculate body (MGB) inputs. As a consequence, the response strength in the $\operatorname{STRF}(\boldsymbol{B} \mathbf{1}, \boldsymbol{a})$ and in the phasic peaks of responses of the PSTH $(\boldsymbol{B}, \boldsymbol{b})$ are increased. This increased excitability also reaches the inhibitory interneuron, leading to a stronger feedforward inhibition, which promotes silent periods between the peaks of discharges $(\boldsymbol{B}, \boldsymbol{C})$ despite an increase in spontaneous firing rate $(\boldsymbol{B} 3, \boldsymbol{d})$. Ultimately, these events lead to improvethe intertrial reliability of temporal patterns. All Ml considered here were based on temporal patterns.

files (compare the responses of neurons 1 and 2 in Fig. 12A3 in control conditions vs after GBZ application in Fig. 12B3; Pola et al., 2003). This view echoes the results obtained by Chechik et al. (2006) who suggested that reduction of redundancy may be a general principle of sensory systems when progressing from the brainstem to the cortex. One can consider that the role of cortical inhibition is to promote neuronal representations that are less correlated with the stimulus acoustic features than those already present at the subcor- 
tical levels. This can be achieved by restricting the emission of action potentials to precise temporal windows, which differ from a cortical site to the next (and from one neuron to the next). This would corroborate the sparse code hypothesis according to which auditory neurons tend to respond to a small number of acoustic features with only a few action potentials (DeWeese et al., 2003; Hromádka et al., 2008) and in a noncorrelated way between each other (Chen et al., 2012). Moreover, it has been shown that alterations of GABAergic inhibition (for example, by estradiol) can affect both the neuronal and behavioral discriminative performance (Tremere and Pinaud, 2011), which suggests that the generation of cortical spike patterns is one of the key elements underlying the perceptual ability to discriminate between communication sounds (Wang et al., 2007; Walker et al., 2008; Shetake et al., 2011).

\section{Conclusions}

Over the past decades, several functional roles have been attributed to cortical inhibition. At the single-cell level, sharpening the functional properties of cortical neurons (frequency tuning in the auditory modality, orientation tuning in the visual system) has been, and is still, one of the most popular hypotheses (for review, see Suga, 1995; Isaacson and Scanziani, 2011), regardless that is achieved by a similar co-tuning of excitation and inhibition, a broad tuning, or no tuning at all of the inhibition (Cardin et al., 2007; Wu et al., 2008; Katzner et al., 2011; Liu et al., 2011). At the network level, a broad base of literature now indicates that inhibition is involved in the generation and the spatial coherence of fast $(20-80 \mathrm{~Hz})$ oscillations (Traub et al., 1996, 1997; Wang and Buzsáki, 1996; Hasenstaub et al., 2005; Atallah and Scanziani, 2009; Cardin et al., 2009; Sohal et al., 2009) and promotes layer selectivity of these oscillations in the somatosensory cortex (Adesnik and Scanziani, 2010). Between these two extremes of a multiscale analysis, our results point out that cortical inhibition can modulate the information content of neuronal responses at both the level of a single cortical site and the map level. Dissecting the mechanisms involved at these different levels of analysis should be a main challenge for future studies, particularly because inhibition dominates sensory responses in waking state (Haider et al., 2013).

\section{References}

Adesnik H, Scanziani M (2010) Lateral competition for cortical space by layer-specific horizontal circuits. Nature 464:1155-1160. CrossRef Medline

Atallah BV, Scanziani M (2009) Instantaneous modulation of gamma oscillation frequency by balancing excitation with inhibition. Neuron 62:566577. CrossRef Medline

Averbeck BB, Lee D (2006) Effects of noise correlations on information encoding and decoding. J Neurophysiol 95:3633-3644. CrossRef Medline

Averbeck BB, Latham PE, Pouget A (2006) Neural correlations, population coding and computation. Nat Rev Neurosci 7:358-366. CrossRef Medline

Bessaïh T, Bourgeais L, Badiu CI, Carter DA, Toth TI, Ruano D, Lambolez B, Crunelli V, Leresche N (2006) Nucleus-specific abnormalities of GABAergic synaptic transmission in a genetic model of absence seizures. J Neurophysiol 96:3074-3081. CrossRef Medline

Brosch M, Schreiner CE (1997) Time course of forward masking tuning curves in cat primary auditory cortex. J Neurophysiol 77:923-943. Medline

Caesar K, Thomsen K, Lauritzen M (2003) Dissociation of spikes, synaptic activity, and activity-dependent increments in rat cerebellar blood flow by tonic synaptic inhibition. Proc Natl Acad Sci U S A 100:16000-16005. CrossRef Medline

Caesar K, Offenhauser N, Lauritzen M (2008) Gamma-aminobutyric acid modulates local brain oxygen consumption and blood flow in rat cerebellar cortex. J Cereb Blood Flow Metab 28:906-915. CrossRef Medline

Calford MB (2002) Mechanisms for acute changes in sensory maps. Adv Exp Med Biol 508:451-460. CrossRef Medline
Cardin JA, Palmer LA, Contreras D (2007) Stimulus feature selectivity in excitatory and inhibitory neurons in primary visual cortex. J Neurosci 27:10333-10344. CrossRef Medline

Cardin JA, Carlén M, Meletis K, Knoblich U, Zhang F, Deisseroth K, Tsai LH, Moore CI (2009) Driving fast-spiking cells induces gamma rhythm and controls sensory responses. Nature 459:663-667. CrossRef Medline

Chechik G, Anderson MJ, Bar-Yosef O, Young ED, Tishby N, Nelken I (2006) Reduction of information redundancy in the ascending auditory pathway. Neuron 51:359-368. CrossRef Medline

Chen C, Read HL, Escabí MA (2012) Precise feature based time scales and frequency decorrelation lead to a sparse auditory code. J Neurosci 32 : 8454-8468. CrossRef Medline

Cox CL, Metherate R, Weinberger NM, Ashe JH (1992) Synaptic potentials and effects of amino acid antagonists in the auditory cortex. Brain Res Bull 28:401-410. CrossRef Medline

Cruikshank SJ, Rose HJ, Metherate R (2002) Auditory thalamocortical synaptic transmission in vitro. J Neurophysiol 87:361-384. Medline

Darbin O, Wichmann T (2008) Effects of striatal GABAA-receptor blockade on striatal and cortical activity in monkeys. J Neurophysiol 99:12941305. CrossRef Medline

Darbin O, Newton L, Wichmann T (2006) A new probe to monitor the effects of drugs on local field potentials. J Neurosci Methods 155:291-295. CrossRef Medline

DeWeese MR, Wehr M, Zador AM (2003) Binary spiking in auditory cortex. J Neurosci 23:7940-7949. Medline

Ebner FF, Armstrong-James MA (1990) Intracortical processes regulating the integration of sensory information. Prog Brain Res 86:129-141. CrossRef Medline

Edeline JM, Weinberger NM (1993) Receptive field plasticity in the auditory cortex during frequency discrimination training: selective retuning independent of task difficulty. Behav Neurosci 107:82-103. CrossRef Medline

Edeline JM, Dutrieux G, Manunta Y, Hennevin E (2001) Diversity of receptive field changes in auditory cortex during natural sleep. Eur J Neurosci 14:1865-1880. CrossRef Medline

Eder HG, Jones DB, Fisher RS (1997) Local perfusion of diazepam attenuates interictal and ictal events in the bicuculline model of epilepsy in rats. Epilepsia 38:516-521. CrossRef Medline

Elhilali M, Fritz JB, Klein DJ, Simon JZ, Shamma SA (2004) Dynamics of precise spike timing in primary auditory cortex. J Neurosci 24:11591172. CrossRef Medline

Gaucher Q, Edeline JM, Gourévitch B (2012) How different are the local field potentials and spiking activities? Insights from multi-electrodes arrays. J Physiol Paris 106:93-103. Medline

Gaucher Q, Huetz C, Gourévitch B, Laudanski J, Occelli F, Edeline JM (2013) How do auditory cortex neurons represent communication sounds? Hear Res. Advance online publication. Retrieved May 21, 2013. doi:10.1016/ j.heares.2013.03.011. CrossRef Medline

Gilbert CD, Wiesel TN (1985) Intrinsic connectivity and receptive field properties in visual cortex. Vision Res 25:365-374. CrossRef Medline

Gourévitch B, Edeline JM (2011) Age-related changes in the guinea pig auditory cortex: relationship with peripheral changes and comparison with tone-induced hearing loss. Eur J Neurosci 34:1953-1965. CrossRef Medline

Gourévitch B, Doisy T, Avillac M, Edeline JM (2009) Follow-up of latency and threshold shifts of auditory brainstem responses after single and interrupted acoustic trauma in guinea pig. Brain Res 1304:66-79. CrossRef Medline

Haider B, Häusser M, Carandini M (2013) Inhibition dominates sensory responses in the awake cortex. Nature 493:97-100. CrossRef Medline

Happel MF, Jeschke M, Ohl FW (2010) Spectral integration in primary auditory cortex attribuable to temporally precise convergence of thalamocortical and intracortical inputs. J Neurosci 30:11114-11127. CrossRef Medline

Hasenstaub A, Shu Y, Haider B, Kraushaar U, Duque A, McCormick DA (2005) Inhibitory postsynaptic potentials carry synchronized frequency information in active cortical networks. Neuron 47:423-435. CrossRef Medline

Hefti BJ, Smith PH (2000) Anatomy, physiology, and synaptic responses of rat layer $\mathrm{V}$ auditory cortical cells and effects of intracellular GABA(A) blockade. J Neurophysiol 83:2626-2638. Medline

Hirsch JA (2003) Synaptic physiology and receptive field structure in the early visual pathway of the cat. Cereb Cortex 13:63-69. CrossRef Medline 
Hromádka T, Deweese MR, Zador AM (2008) Sparse representation of sounds in the unanesthetized auditory cortex. PLoS Biol 6:e16. CrossRef Medline

Huetz C, Del Negro C, Lebas N, Tarroux P, Edeline JM (2006) Contribution of spike timing to the information transmitted by HVC neurons. Eur J Neurosci 24:1091-1108. CrossRef Medline

Huetz C, Philibert B, Edeline JM (2009) A spike-timing code for discriminating conspecific vocalizations in the thalamocortical system of anesthetized and awake guinea pigs. J Neurosci 29:334-350. CrossRef Medline

Huetz C, Gourévitch B, Edeline JM (2011) Neural codes in the thalamocortical auditory system: from artificial stimuli to communication sounds. Hear Res 271:147-158. CrossRef Medline

Isaacson JS, Scanziani M (2011) How inhibition shapes cortical activity. Neuron 72:231-243. CrossRef Medline

Jones MS, Barth DS (2002) Effects of bicuculline methiodide on fast $(>200$ $\mathrm{Hz}$ ) electrical oscillations in rat somatosensory cortex. J Neurophysiol 88:1016-1025. Medline

Joris PX (2003) Interaural time sensitivity dominated by cochlea-induced envelope patterns. J Neurosci 23:6345-6350. Medline

Joris PX, Schreiner CE, Rees A (2004) Neural processing of amplitudemodulated sounds. Physiol Rev 84:541-577. CrossRef Medline

Katzner S, Busse L, Carandini M (2011) $\mathrm{GABA}_{\mathrm{A}}$ inhibition controls response gain in visual cortex. J Neurosci 31:5931-5941. CrossRef Medline

Kurt S, Crook JM, Ohl FW, Scheich H, Schulze H (2006) Differential effects of iontophoretic in vivo application of the GABA(A)-antagonists bicuculline and gabazine in sensory cortex. Hear Res 212:224-235. CrossRef Medline

Latham PE, Nirenberg S (2005) Synergy, redundancy, and independence in population codes, revisited. J Neurosci 25:5195-5206. CrossRef Medline

Liu BH, Li YT, Ma WP, Pan CJ, Zhang LI, Tao HW (2011) Broad inhibition sharpens orientation selectivity by expanding input dynamic range in mouse simple cells. Neuron 71:542-554. CrossRef Medline

Mann EO, Kohl MM, Paulsen O (2009) Distinct roles of $\mathrm{GABA}_{\mathrm{A}}$ and $\mathrm{GABA}_{\mathrm{B}}$ receptors in balancing and terminating persistent cortical activity. J Neurosci 29:7513-7518. CrossRef Medline

Manunta Y, Edeline JM (1997) Effects of noradrenaline on frequency tuning of auditory cortex neurons. Eur J Neurosci 9:833-847. CrossRef Medline

Manunta Y, Edeline JM (1998) Effects of noradrenaline on rate-level function of auditory cortex neurons: is there a gating effect of noradrenaline? Exp Brain Res 118:361-372. CrossRef Medline

Manunta Y, Edeline JM (1999) Effects of noradrenaline on frequency tuning of auditory cortex neurons during wakefulness and slow-wave sleep. Eur J Neurosci 11:2134-2150. CrossRef Medline

Metherate R, Ashe JH (1994) Facilitation of an NMDA receptor-mediated EPSP by paired-pulse stimulation in rat neocortex via depression of GABAergic IPSPs. J Physiol 481:331-348. Medline

Narayanan NS, Kimchi EY, Laubach M (2005) Redundancy and synergy of neuronal ensembles in motor cortex. J Neurosci 25:4207-4216. CrossRef Medline

Narayan R, Graña G, Sen K (2006) Distinct time scales in cortical discrimination of natural sounds in songbirds. J Neurophysiol 96:252-258. CrossRef Medline

Narayan R, Best V, Ozmeral E, McClaine E, Dent M, Shinn-Cunningham B, Sen K (2007) Cortical interference effects in the cocktail party problem. Nat Neurosci 10:1601-1607. CrossRef Medline

Oswald AM, Schiff ML, Reyes AD (2006) Synaptic mechanisms underlying auditory processing. Curr Opin Neurobiol 16:371-376. CrossRef Medline

Pinaud R, Terleph TA, Tremere LA, Phan ML, Dagostin AA, Leão RM, Mello CV, Vicario DS (2008) Inhibitory network interactions shape the auditory processing of natural communication signals in the songbird auditory forebrain. J Neurophysiol 100:441-455. Medline

Pola G, Thiele A, Hoffmann KP, Panzeri S (2003) An exact method to quantify the information transmitted by different mechanisms of correlational coding. Network 14:35-60. CrossRef Medline

Recanzone GH (2008) Representation of con-specific vocalizations in the core and belt areas of the auditory cortex in the alert macaque monkey. J Neurosci 28:13184-13193. CrossRef Medline

Riquimaroux H, Gaioni SJ, Suga N (1991) Cortical computational maps control auditory perception. Science 251:565-568. CrossRef Medline

Riquimaroux H, Gaioni SJ, Suga N (1992) Inactivation of the DSCF area of the auditory cortex with muscimol disrupts frequency discrimination in the mustached bat. J Neurophysiol 68:1613-1623. Medline

Robertson D, Irvine DR (1989) Plasticity of frequency organization in auditory cortex of guinea pigs with partial unilateral deafness. J Comp Neurol 282:456-471. CrossRef Medline

Rosen MJ, Mooney R (2003) Inhibitory and excitatory mechanisms underlying auditory responses to learned vocalizations in the songbird nucleus HVC. Neuron 39:177-194. CrossRef Medline

Schnupp JW, Hall TM, Kokelaar RF, Ahmed B (2006) Plasticity of temporal pattern codes for vocalization stimuli in primary auditory cortex. J Neurosci 26:4785-4795. CrossRef Medline

Shannon CE (1948) A mathematical theory of communication. Bell System Technical J 27:379-423.

Shetake JA, Wolf JT, Cheung RJ, Engineer CT, Ram SK, Kilgard MP (2011) Cortical activity patterns predict robust speech discrimination ability in noise. Eur J Neurosci 34:1823-1838. CrossRef Medline

So K, Ganguly K, Jimenez J, Gastpar MC, Carmena JM (2012) Redundant information encoding in primary motor cortex during natural and prosthetic motor control. J Comput Neurosci 32:555-561. CrossRef Medline

Sohal VS, Zhang F, Yizhar O, Deisseroth K (2009) Parvalbumin neurons and gamma rhythms enhance cortical circuit performance. Nature 459: 698-702. CrossRef Medline

Suga N (1995) Sharpening of frequency tuning by inhibition in the central auditory system: tribute to Yasuji Katsuki. Neurosci Res 21:287-299. CrossRef Medline

Swadlow HA (2003) Fast-spike interneurons and feedforward inhibition in awake sensory neocortex. Cereb Cortex 13:25-32. CrossRef Medline

Tachibana Y, Kita H, Chiken S, Takada M, Nambu A (2008) Motor cortical control of internal pallidal activity through glutamatergic and GABAergic inputs in awake monkeys. Eur J Neurosci 27:238-253. CrossRef Medline

Tan AY, Zhang LI, Merzenich MM, Schreiner CE (2004) Tone-evoked excitatory and inhibitory synaptic conductances of primary auditory cortex neurons. J Neurophysiol 92:630-643. CrossRef Medline

Traub RD, Whittington MA, Stanford IM, Jefferys JG (1996) A mechanism for generation of long-range synchronous fast oscillations in the cortex. Nature 383:621-624. CrossRef Medline

Traub RD, Jefferys JG, Whittington MA (1997) Simulation of gamma rhythms in networks of interneurons and pyramidal cells. J Comput Neurosci 4:141-150. CrossRef Medline

Tremere LA, Pinaud R (2011) Brain-generated estradiol drives long-term optimization of auditory coding to enhance the discrimination of communication signals. J Neurosci 31:3271-3289. CrossRef Medline

Walker KM, Ahmed B, Schnupp JW (2008) Linking cortical spike pattern codes to auditory perception. J Cogn Neurosci 20:135-152. CrossRef Medline

Wallace MN, Palmer AR (2008) Laminar differences in the response properties of cells in the primary auditory cortex. Exp Brain Res 184:179-191. Medline

Wallace MN, Rutkowski RG, Palmer AR (2000) Identification and localisation of auditory areas in guinea pig cortex. Exp Brain Res 132:445-456. CrossRef Medline

Wang J, Caspary D, Salvi RJ (2000) GABA-A antagonist causes dramatic expansion of tuning in primary auditory cortex. Neuroreport 11: 1137-1140. CrossRef Medline

Wang J, McFadden SL, Caspary D, Salvi R (2002) Gamma-aminobutyric acid circuits shape response properties of auditory cortex neurons. Brain Res 944:219-231. CrossRef Medline

Wang L, Narayan R, Graña G, Shamir M, Sen K (2007) Cortical discrimination of complex natural stimuli: can single neurons match behavior? J Neurosci 27:582-589. CrossRef Medline

Wang X, Chen G, Gao W, Ebner T (2009) Long-term potentiation of the responses to parallel fiber stimulation in mouse cerebellar cortex in vivo. Neuroscience 162:713-722. CrossRef Medline

Wang XJ, Buzsáki G (1996) Gamma oscillation by synaptic inhibition in a hippocampal interneuronal network model. J Neurosci 16:6402-6413. Medline

Wehr M, Metherate R (2011) Synaptic integration in auditory cortex. In: The auditory cortex (Winer JA, Schreiner CE, eds), pp 235-250. New York: Springer.

Wehr M, Zador AM (2003) Balanced inhibition underlies tuning and sharpens spike timing in auditory cortex. Nature 426:442-446. CrossRef Medline 
Wehr M, Zador AM (2005) Synaptic mechanisms of forward suppression in rat auditory cortex. Neuron 47:437-445. CrossRef Medline

Wu GK, Arbuckle R, Liu BH, Tao HW, Zhang LI (2008) Lateral sharpening of cortical frequency tuning by approximately balanced inhibition. Neuron 58:132-143. CrossRef Medline

Yu H, Chen X, Sun C, Shou T (2008) Global evaluation of contributions of
GABA A, AMPA and NMDA receptors to orientation maps in cat's visual cortex. Neuroimage 40:776-787. CrossRef Medline

Yuan K, Shih JY, Winer JA, Schreiner CE (2011) Functional networks of parvalbumin-immunoreactive neurons in cat auditory cortex. J Neurosci 31:13333-13342. CrossRef Medline 